\title{
DESCARGOS, DIARIOS Y PALINODIAS: ALGUNOS EJEMPLOS DE LITERATURA MEMORIALÍSTICA EN LA GENERACIÓN DEL 36
}

\author{
Joaquín JUAN PENALVA \\ Universidad de Alicante
}

\section{BREVE APROXIMACIÓN AL GÉNERO DE LAS MEMORIAS EN LOS AUTORES DEL 36}

Aunque los libros de memorias no son, en sentido estricto, autobiografías, sí comparten con ellas algunos de sus rasgos fundamentales, empezando por su inserción dentro de lo que la teoría de géneros ha acotado como literatura autobiográfica. La autobiografía, de hecho, es entendida como una forma de biografía en la que el biógrafo y el biografiado son la misma persona. A pesar de la existencia de novelas que puedan adoptar la forma autobiográfica, la autobiografía no es un género de ficción, pues se encuentra a medio camino entre la literatura y la historia. Al igual que se establece una tipología de biografías -biografía crítica, informativa, interpretativa-, la escritura autobiográfica puede manifestarse de muy diversas formas, más o menos tipificadas: autobiografía en su significado más restringido, memorias, diarios, cartas, palinodias...

Podemos establecer una diferenciación entre aquellos textos de cariz autobiográfico que fueron escritos para ser difundidos -es el caso de las autobiografías y de los libros de memorias- y aquellos otros que, en principio, no iban a ser publicados, pero vieron la luz tras la muerte del autor -diarios, cartas y demás documentos de carácter íntimo-. Lo más interesante de éstos es que se fueron escribiendo a lo largo de toda una vida, y no hay en ellos el grado de autodefensa o autojustificación que suele haber en los primeros, que son recreaciones del 
pasado desde el presente, aunque el autor en cuestión pueda valerse para su composición de cartas o diarios. Por otro lado, en las autobiografías todo se focaliza en torno al biografiado-biógrafo; no así en los libros de memorias, donde el foco de atención recae sobre su entorno, amistades y compañías. De este modo, el autor del libro de memorias no hablará sólo de sí mismo, sino de sí mismo en relación con el mundo cultural, político o social al que pertenezca.

En nuestro caso, nos ocuparemos de una serie de intelectuales que, además de ser poetas, ensayistas, prosistas, dramaturgos o filósofos, hubieron de jugar un importante papel en el panorama intelectual de la postguerra española, iniciando lo que fue una controvertida aventura de reconstrucción cultural durante el franquismo. Se trata de los autores de la llamada generación del 36, aquellos intelectuales que se formaron durante los años de la República, publicaron sus primeros libros en torno a 1936 y cuya carrera se vio interrumpida -en algunos casos definitivamente, en otros sólo temporalmente-por la Guerra Civil.

En principio hemos aceptado sin más el marbete de generación del 36, pero no se trata de un concepto exento de problemas, ni mucho menos. Lo utilizamos porque se admite generalmente para referirse a una serie de autores - no sólo poetas- que sufrieron, cuando eran jóvenes, la Guerra Civil, y que se vieron obligados a luchar -no sólo con las armas, sino también con las letras- a favor de uno de los bandos en liza. Guillermo Díaz-Plaja, autor que, por muchas razones, debe figurar en la nómina de escritores asociados a ese concepto de generación del 36, ha acuñado un término clave para entender a este grupo; él formula el concepto de «generación destruida», y lo hace, no para hablar de la Guerra Civil, sino para referirse al largo período que se abrió tras la contienda:

A mi juicio, nuestra generación fue una promoción sacrificada. Demasiado joven en 1936, nos sentimos, de pronto, demasiado viejos en 1939. Vimos caer derribados muchos de nuestros ídolos y nos agarramos desesperadamente al salvavidas de la supervivencia, con un intento primario y vegetativo de subsistir. Por otra parte, nuestros maestros -los de la decantada y esteticista generación de 1927- no sólo no se mantuvieron en su altiva aristocracia estética, sino que se nos derribaron en los desafueros del existencialismo, cuando no del «pop-art». Nos quedamos, pues, desfasados, sin brújula y sin maestros, navegando como Dios nos dio a entender (Díaz-Plaja 1966, p. 179).

He ahí, en estas palabras de Díaz-Plaja, una de las características que marcaron definitivamente el devenir intelectual e histórico de este grupo de intelectuales: la ausencia de maestros. En realidad, se trata también de una ausencia física, pues la mayor parte de la intelectualidad española ya no vive en España tras la contienda. Evidentemente, ese exilio de la intelectualidad afectó también a la 
generación en ciernes, pues muchos de los autores que figuran en la nómina de la generación del 36 ya no regresaron a España tras 1939. Por tanto, de aquel grupo de intelectuales que velaron sus armas literarias en los años de la República, sólo permanecieron en España los que apoyaron al bando de los vencedores o los que, en todo caso, no apoyaron abiertamente al de los vencidos. Es, efectivamente, un grupo escindido, cuyos miembros se vieron obligados a abandonarlo cuando todavía no estaba plenamente configurado. Sin embargo, aquellos intelectuales que sí permanecieron en España, aunque todavía eran bastante jóvenes, se vieron en el brete de llevar la iniciativa en todas y cada una de las empresas culturales que se promovieron en la inmediata postguerra -es el caso, por ejemplo, de la revista Escorial, cuyo primer número vio la luz en noviembre de 1940 bajo la dirección de Dionisio Ridruejo y Pedro Laín Entralgo, y entre cuyos colaboradores figuró íntegra la nómina de autores del 36 que permanecieron en España tras la contienda-. Junto a ellos, maestros como Manuel Machado, Gerardo Diego o Eugenio d'Ors, que ejercían cierta tutela sobre los jóvenes; se intentaba, por tanto, paliar esa incipiente ausencia de maestros.

Muchos de aquellos jóvenes -es el caso de Rosales, Laín y, sobre todo, Ridruejo, el de más alto cargo de todos ellos- habían militado en las filas de Falange, pero eso no les impidió abrir ciertos resquicios de tolerancia y liberalismo en los años más oscuros del franquismo, ya que, según lo ha formulado José-Carlos Mainer, este grupo se encontraba «atenazado entre una vocación intelectual de signo liberal y el atractivo señuelo de la revolución nacional y una suerte de totalitarismo del espíritu» (Mainer 1971, pp. 54-55). Ese supuesto liberalismo se ha discutido mucho luego, a la luz de las respectivas evoluciones ideológicas de los miembros del grupo. Acudimos de nuevo a Guillermo Díaz-Plaja, que retrata a esta joven intelectualidad de los años 40 , cargando las tintas en el tópico del evasionismo:

Un mundo nuevo nos venía entre jadeantes laureles militares. Y, curiosamente, aquellos poetas que llevaban botas de montar, venían cantando melifluos temas esteticistas, en sonetos perfectos y prosas con volutas, Dios, paisaje, levantado amor. La sangre estaba ahí; y las ruinas atroces; y los muñones patéticos y las tristes heridas. Y tanta muerte. Pero si repasamos las revistas literarias españolas del año 40 nos sorprenderá un atildado sentido de la belleza, un anhelo de noble perfección retórica. Continuaban estos escritores una manera decorosa y académica que en la prosa venía del estilo senatorial que había puesto de moda la escuela «del Pirineo»-Mourlane, Basterra, Sánchez Mazas, Eugenio Montes, Víctor de la Serna-, y en el verso se apuntaba al modo neoclásico que habían lanzado en 1935 Luis Rosales, los hermanos Panero y Germán Bleiberg. 
¿Cómo imaginar, entre tanta cicatriz todavía encendida, esta derivación a la retórica noble y al tema estético? El nombre de Garcilaso -que esa juventud blandió como bandera- puede servirnos de explicación. He aquí ese brío militar -ese «claro caballero de rocío», como le llamó Miguel Hernández- trepidando en los campos de guerra de Europa y de África; helo aquí sonando a hierro y mojado de sudor y de sangre, al servicio del César, herido en Túnez y muerto en Fréjus. Estos temas asoman bien fugazmente en sus versos. La poesía es para él una dulce fuga a lo que se añora, justamente hacia lo que no se tiene. Se canta porque no se ve: prados de paz, ninfas en el río, abejas susurrantes (Díaz-Plaja 1966, pp. 42-43).

Díaz-Plaja los acusa de evasionismo, pero eso, al final, se ha convertido en tópico y sólo responde a una parcela de la realidad. Lo cierto es que hubo un intento decidido por recuperar parte de la cultura española anterior a la Guerra Civil. Se pretendía así establecer unas raíces sólidas sobre las cuales asentar la reconstrucción cultural durante la alta postguerra. Por supuesto, también se escribieron versos a la novia y a todos aquellos que el bando vencedor consideró héroes, mártires y caudillos de la Guerra Civil. Ahora bien, en el caso de la revista Escorial, una publicación de cultura y letras sufragada por el régimen, lo que se intenta es recuperar la tradición de las revistas culturales publicadas durante los años de la República. Era un intento, en definitiva, de buscar una línea que permitiera continuar la tradición literaria, aunque eso implicara algunas concesiones a la oficialidad.

Nos ocuparemos a partir de ahora de algunos de los libros de memorias, diarios y palinodias que nos han legado los miembros más representativos de la generación del 36', concretamente los que protagonizaron la labor de reconstruc-

${ }^{1}$ En un artículo ya clásico de Ricardo Gullón encontramos una vasta nómina de autores vinculados a la generación del 36 . Se trata de una información de primera mano sobre los protagonistas, ya que el propio Gullón figuró entre los críticos y prosistas de esa generación. Los criterios generacionales que sigue no son rígidos, pero nos proporciona la nómina más completa: «Llegado a este punto considero conveniente señalar los nombres de quienes, a mi juicio, figuran en la generación de 1936. No entro en materia sin antes haber reflexionado sobre el criterio más adecuado para redactar la nómina de quienes la constituyen, advirtiendo desde luego que queda abierta a eventuales rectificaciones; después de algunas vacilaciones he optado por aceptar una norma algo ambigua, pero bastante clara, que tiene en cuenta simultáneamente la edad, la dedicación a la literatura en la fecha (1936) señalada como definitoria de la generación, la convivencia, la publicación en las mismas revistas, colecciones literarias, diarios y otras publicaciones, y la participación en las experiencias de la época desde los mismos círculos de acción. / Los poetas de la generación, según esta norma, serían: Miguel Hernández, Luis Rosales, Leopoldo y Juan Panero, Luis Felipe Vivanco, Ildefonso-Manuel Gil, Germán Bleiberg, José Antonio Muñoz Rojas, José María Luelmo, Pedro Pérez Clotet, Rafael Duyos, Gabriel Celaya, Arturo Serrano Plaja y Juan Gil Albert. En el grupo de prosistas figurarían: Enrique Azcoaga, José Antonio Maravall, Antonio Sánchez Barbudo, Ramón Faraldo, Eusebio García 
ción cultural que se ha venido apuntando, esto es, los que ganaron la guerra. Nos centraremos específicamente en algunos de los autores que, de modo más temprano, se vieron obligados a justificar el papel que jugaron en Ia España de la Guerra Civil y, sobre todo, después, durante el franquismo. Se trata, por tanto, de autores que, en un primer momento, apoyaron decididamente al bando de los sublevados, pero que, conforme se estableció el nuevo régimen, se fueron desengañando y desencantando hasta desembocar en una disidencia más o menos explícita, más o menos militante. Se trata de intelectuales que, falangistas de primera o segunda hornada, resultaron vencedores en la guerra, pero, a la postre, fueron los grandes vencidos de la postguerra.

Con el paso de los años, algunos de los intelectuales que, durante la Guerra Civil, apoyaron la sublevación militar, fueron viendo frustradas muchas de sus ilusiones, alejándose, de una manera más o menos explícita, de los núcleos de poder. Así, el primer caso sonado de disidencia fue el de Dionisio Ridruejo, quien, a su regreso de la campaña de Rusia, dimitió de todos sus cargos políticos. A éste le siguieron personalidades como Pedro Laín, apartado del rectorado de la Universidad de Madrid en 1956, y José Luis López Aranguren, expulsado de su cátedra de Ética y Sociología en 1965. Todos ellos han narrado sus memorias en sendos volúmenes donde ponen de manifiesto su evolución ideológica. Además, también contamos con el Diario de Luis Felipe Vivanco, un texto que, al contrario que los libros de memorias de los autores mencionados, es de carácter íntimo. Por supuesto, no son los únicos testimonios, pero sí los más representativos para dar cuenta de esa evolución ideológica hacia el desencanto sufrida por este grupo de intelectuales.

Estos libros, especialmente Descargo de conciencia y Casi unas memorias, aparecieron rodeados de un aura de polémica, y, de hecho, han despertado diversas controversias. Sin embargo, no debemos olvidar que son textos fundamentales para reconstruir todo un período cultural, aunque deben ser leídos en todo momento bajo una perspectiva crítica. Estos autores han sido muy criticados, pero todos ellos han evolucionado hasta posiciones liberales e incluso democráticas,

Luengo, María Zambrano, Antonio Rodríguez Moñino, José Ferrater Mora y yo mismo. / A este núcleo central de la generación es preciso añadir los nombres de quienes se incorporan a ella durante la guerra civil, o inmediatamente después de acabar ésta, y que desde antes puede decirse que figuraban idealmente junto a los ya dichos: Dionisio Ridruejo, José Luis Cano, Ramón de Garciasol, Pedro Laín Entralgo, Juan López Morillas, José Luis Aranguren, Francisco Yndurain, Julián Marías, Segundo Serrano Poncela, José Antonio Gaya Nuño, José Suárez Carreño, Jorge Campos, Ernesto G. da Cal y José Manuel Blecua. Hay escritores de incorporación más tardía, pero a quienes no sería abusivo incluir entre los recién citados: ejemplos, Concha Zardoya, Juan Ruiz Peña, Luis Monguió, Carlos Clavería y Antonio Rodríguez Huéscar» (Gullón, 1969, pp. J66-167). 
como es el caso de Ridruejo. Su liberalismo, al igual que el de la revista Escorial, es perfectamente discutible, pero no se puede negar un intento de apertura, más o menos tímido. De todas maneras, para cierto sector de la crítica, Escorial no fue un reducto de aperturismo, sino una revista netamente fascista que se «liberalizaba» a posteriori a raíz de la evolución ulterior de sus fundadores. Es una lectura posible, pero, en todo caso, quizá habría que reconocer, por lo menos, que en esa revista ya estaba presente la semilla de la posterior evolución ideológica de sus fundadores. En este sentido, queremos hacernos eco de algunas afirmaciones de Félix Grande, quien, en «La poesía de Luis Rosales: más junta que una lágrima», habla en términos de deuda «de honor» con respecto a estos autores que aquí nos ocupan:

Quede apuntado únicamente como señal de una deuda -quizá cabría decir «de honor»-que todavía tenemos contraída con una generación a la que no se ha reconocido el lento y silencioso -y pienso que efectivo- esfuerzo que llevó a cabo para contribuir, con la seriedad del trabajo continuado y de un liberalismo fundamental, y por tanto fundante, a la restitución del eslabonamiento de nuestra cultura. [...] Todos ellos lo hicieron, como he dicho, porque eran liberales. También, inteligentes, dándole a la palabra lo que contiene de esfuerzo, de rigor y de premonición. Pero también por otra causa: porque, nacidos a la vida en época de libertad, renacieron de entre ruinas, entre saña y destrozos, y ello les hizo ahondar en sí mismos y en lo cordial de la cultura, ello les hizo ir a la búsqueda de la intimidad de la vida, lo que quedaba en pie por entre los cascotes de una España destrozada y amordazada. Su mirada interior, su palabra interior, la casi mendicante intimidad que reinaugura su poética no fue, pues, otra cosa que un programa de reconstrucción (Grande 1996, p. 17).

A partir de ahora, nos centraremos en algunos de los títulos arriba apuntados. En primer lugar, hablaremos de dos obras de José Luis López Aranguren, una de carácter netamente autobiográfico y otra de carácter misceláneo. Después nos ocuparemos de las memorias de Pedro Laín Entralgo y Dionisio Ridruejo, de mayor proyección pública, debido al papel político jugado por sus autores. Por último, nos detendremos en el Diario de Luis Felipe Vivanco, como ya se indicó.

\section{JOSÉ LUIS LÓPEZ ARANGUREN: CRÍTICA Y MEDITACIÓN Y MEMORIAS Y ESPERANZAS ESPAÑOLAS}

Aranguren publicó en febrero de 1957 su libro Crítica y meditación, donde reunía una serie de textos que hasta ese momento habían ido apareciendo de manera dispersa en diversas publicaciones. Entre ellos encontramos algunos de cariz autobiográfico, que son los que aquí nos interesan. Crítica y meditación no 
es, en sentido estricto, un libro de memorias, lo que ocurre es que en él está la semilla o germen de lo que será Memorias y esperanzas españolas, que sí es propiamente un libro autobiográfico: «Sobre Crítica y meditación volví, hasta el autoplagio, en Memorias y esperanzas españolas y, siempre que me vea obligado a hablar de mí -tema que, como he dicho otras veces, me parece poco interesante- tendré que volver a este libro» (Aranguren 1977, p. 8).

Si nos interesa Crítica y meditación es fundamentalmente porque en su introducción de 1977 Aranguren da cuenta de la relación personal e intelectual que estableció con algunos miembros de la generación del 36, concretamente con Pedro Laín Entralgo y con Dionisio Ridruejo: «Es parte de mi biografía en y con un grupo de poetas, y de nuestro sentido poético de entonces. La relación con la llamada generación del 36 es vista, más en general, con respecto a sus dos miembros más políticamente representativos, Dionisio Ridruejo y Pedro Laín» (Aranguren 1977, p. 8). En la nota preliminar que precedía al texto en la primera edición, Aranguren ya indicaba el carácter misceláneo de los artículos que conformaban el volumen:

Se reúnen en este volumen, por el orden cronológico de su publicación primera dentro de cada uno de los grupos en que se reparten, una serie de artículos que coinciden, negativamente, en no ser de tema religioso ni técnicamente filosófico. Casi todos -pero no todos- son de crítica literaria. A casi todos -pero no a todos- les es común también un cierto fondo y acento líricos. No sé si tan escasas, tan incompletas coincidencias autorizan a juntarlos, haciéndolos pasar por un libro. Cedo con ello a amable requerimiento editorial. De cualquier modo, y eso sí que puedo afirmarlo sin reservas, todas las meditaciones que siguen se alimentan del recuerdo, de la poesía, del amor, de la amistad, de la esperanza (Aranguren 1977, p. 13).

El libro está dividido en tres partes: «Primera parte», «Intermedio» y «Segunda parte». Aquí nos interesa fundamentalmente el «Intermedio», pues es allí donde Aranguren recoge aquellos artículos de carácter autobiográfico. Sin embargo, antes de pasar a esos textos quisiera referirme brevemente al resto de artículos de Crítica y meditación. En la «Primera parte» encontramos sobre todo reflexiones sobre la poesía, principalmente referidas a la generación del 36, de cuyos miembros Aranguren se sintió compañero en un primer momento de la postguerra; así ocurre en «Poesía y existencia», «Despedida y umbral» y «La poesía de nuestra vida». Junto a estos artículos también aparecen otros de carácter más general, hasta llegar a «Tiempo para la novela», que es el que cierra esta primera parte. 
La «Segunda parte» consta de una serie de cinco artículos: «Aprecio de don Pedro Mourlane», «La muerte de Eugenio d'Ors», «Sentido ético de las ficciones novelescas orsianas», «La evolución espiritual de los intelectuales españoles en la emigración» y «Pedro Laín, el problema de España y la esperanza española». De todos ellos, el más extenso, y también el más importante, es el penúltimo, pues supone el primer intento realizado desde la península por estudiar la obra de todos aquellos intelectuales que, tras la Guerra Civil, abandonaron España-recordemos, además, que una parte nada desdeñable de la generación del 36 también estaba en el exilio-. El último artículo también es interesante, pues se focaliza en la figura de Pedro Laín; a él volveremos cuando hablemos de Descargo de conciencia.

Cinco textos se dan cita en ese «Intermedio» que, como se ha dicho, va a centrar nuestros esfuerzos: «Meditación de "El Cerezo"», «Todos los hombres somos hermanos (relato)», «Aprendido en la vida», «Nuestra Señora del Recuerdo» $\mathrm{y}$ «A propósito de nuestra generación». El primero de los artículos es un texto reflexivo escrito a partir de una estancia del autor en el campo. El segundo, tal y como se explicita en el subtítulo, es un relato breve o cuento de tema familiar. "Aprendido en la vida» es, de nuevo, un texto donde Aranguren reflexiona sobre la vida deteniéndose en tres personajes: sus propios hijos y una muchacha que conoció años atrás y que ahora le viene a la mente al enterarse que es epiléptica. Sin embargo, los que más nos interesan aquí son los dos últimos.

«Nuestra Señora del Recuerdo» es un texto fundamental, tanto, que Aranguren lo incorporó, tal y como aparece en Crítica y meditación, en Memorias y esperanzas españolas. Está dedicado a José Antonio Muñoz Rojas, poeta de la generación del 36. En él, el autor se refiere a una segunda persona que es precisamente el amigo de la infancia, el compañero de internado, y relata su estancia en el colegio que los jesuitas regentaban en Chamartín de la Rosa. Recuerda los años de la niñez, cuando coincidió con Muñoz Rojas en Nuestra Señora del Recuerdo. Al final del artículo, Aranguren nos cuenta cómo, en un momento próximo a la redacción del mismo, volvió de nuevo al colegio, con motivo de la fiesta de la Inmaculada. Fue allí para intentar recordar cómo había sido él en aquellos momentos, antes de que los años le pasaran por encima. Curiosamente, Muñoz Rojas, a quien va dedicado «Nuestra Señora del Recuerdo», recrea aquellos mismos momentos en La gran musaraña, libro de memorias publicado en 1994 donde el poeta antequerano recuerda sus años de infancia, juventud y primera madurez, poniendo como límite temporal de su relato el fin de la Guerra Civil. En La gran musaraña, Muñoz Rojas le dedica unas emotivas líneas a José Luis López Aranguren, que reproducimos a continuación: 
El único alumno contemporáneo que habría de sobresalir entre mis compañeros de Chamartín fue José Luis López Aranguren, que me precedía en un curso, pero con el que año sí y año no, coincidía en la «División». José Luis era mi envidia, no por sus calidades intelectuales, sino por el impecable corte de sus trajes y el perfecto almidonado de sus cuellos, en contraste con los míos con su inevitable toque pueblerino, que tanto me hacía sufrir. Era larguirucho, sin las angulosidades que con la edad ha ido colmando sus perfiles, muy repeinado entonces siempre. Aunque no compañeros estrictos de clase, sí recuerdo una relación cordial, sin saber los motivos, ya que por lo general los alumnos de cursos superiores miraban con indiferencia, si no desdén, a los de los inferiores. José Luis era un alumno modelo, se llevaba todos los premios, obtenía todas las dignidades, era Príncipe o Regulador, algo importante. Luego la vida en sus pasos contados y no contados nos ha vuelto a unir y separar, siguiendo sus avatares. De aquellos años existe su precioso testimonio, publicado en la sección «También entre los libros anda el Señor» del Correo Literario, escrito en esa prosa tersa, para mí la mejor entre las de los ensayistas de su generación. Mi relación con José Luis se consolidó años adelante en las Conversaciones de Gredos que dirigía el inolvidable Alfonso Querejazu y que reunía un grupo de intelectuales liberales, de distintas procedencias y destinos (Muñoz Rojas 1994, pp. 87-88).

El artículo que cierra «Intermedio» es «A propósito de nuestra generación», donde, aprovechando un texto de Dionisio Ridruejo de reciente publicación, Aranguren decide situarse a cierta distancia de sus compañeros de generación. Allí confiesa que «no me siento completamente embarcado con mi generación ni, por tanto, completamente separado, en cierto modo, de los que surcan el océano de la historia de los navíos que vienen detrás del nuestro» (Aranguren 1977, p. 108). Bien es cierto que Aranguren se incorporó a este grupo de intelectuales tardíamente, por eso no resulta extraño que se alejara de ellos en cuanto se dio cuenta de que habían pecado de ingenuos al pensar que serían capaces de reconstruir la cultura española con la aquiescencia del régimen establecido. Aranguren, por otra parte, es uno de los autores que, de manera más temprana y constante, inició una labor de autocrítica, tal como lo ha señalado Thomas Mermall: «Aranguren demostró estar mejor dispuesto hacia las exigencias de la secularización que su amigo Laín, y su crítica de la sociedad española, especialmente del catolicismo oficial, fue más abierta y explícita que la de cualquier miembro católico de su generación» (Mermall 1978, p. 123).

Donde la prosa de José Luis López Aranguren alcanza un grado mayor de autobiografismo es precisamente en Memorias y esperanzas españolas. Aunque figuró en las filas de la generación del 36, lo cierto es que no jugó un papel público a la manera en que lo hicieron Dionisio Ridruejo o Pedro Laín Entralgo; de ahí 
que su particular libro de memorias ofrezca algunas características propias. De hecho, Memorias y esperanzas españolas no es una autobiografía en sentido estricto, como tampoco un libro de memorias en clave de palinodia; se trata, en realidad, de una autobiografía intelectual a lo largo de cuyas páginas el autor va relatando su labor como tal dentro de unos años bastante conflictivos. Es un texto más introspectivo, en cierto modo, que la palinodia de Pedro Laín, por un lado, y mucho menos exhaustivo que Casi unas memorias, de Ridruejo, donde se convocan textos de diversa procedencia -cartas, artículos, reflexiones del autor y demás-, por otro. En el caso de Aranguren, lo que tenemos es una reflexión sobre la propia vida en tanto que intelectual. En principio, Memorias y esperanzas españolas fue un libro de encargo que Aranguren preparó, por sugerencia de Jean Sur, para Editions du Centurion, de París. Sin embargo, conforme fue creciendo el libro y convirtiéndose en más «español», su autor se decidió a publicarlo en una editorial española:

Para la edición española se me ocurrió una editorial catalana. Dos razones me movieron a cambiar de propósito. He pensado que el primer libro que vuelva a publicar en Cataluña debe ser sobre Cataluña, sobre mis lazos afectivos con ella y sobre mi idea, en todos los órdenes, de lo catalán en el contexto ibérico. Por otra parte, entregando esta obra a Taurus Ediciones, celebraba la reciente promoción dentro de la casa de mi querido e intelectualmente muy estimado amigo Jesús Aguirre, y continuaba además con su primera parte las únicas prosas autobiográficas que hasta ahora había escrito, publicadas en Taurus bajo el título de Crítica y meditación; al comenzar el presente libro con unas páginas tomadas de allí, refrendaba, por así decirlo, el copyright (Aranguren 1969, pp. 9-10).

Memorias y esperanzas españolas se divide en veinte capítulos breves, precedidos por una introducción donde el autor se interroga sobre lo que es y no es este libro. Desde un primer momento, niega la idea de que se trate de un libro de memorias al uso: «No me es fácil decir, y menos desde su primera página, en qué va a consistir este libro. ¿Será un libro de memorias? No, al menos no sin más. Pues mirará al futuro tanto como al pasado. Más aún que al pasado» (Aranguren 1969 , p. 13). Del mismo modo, tampoco acepta que sea una autobiografía convencional -«No hablaré de mí solo; hablaré de mí con los demás, de la influencia de los demás sobre mí» (Aranguren 1969, p. 13)-. Por tanto, si no es un libro de memorias ni una autobiografía, ¿qué puede ser? ¿Unas confesiones, al estilo de las de San Agustín? Tampoco. Se trata, en realidad, de un libro donde el autor aborda su faceta de intelectual en relación con los otros: «Yo diría más bien que lo que voy a hacer es tratar de descubrir el sentido que he querido dar a mi acción intelectual» (Aranguren 1969, p. 14). En definitiva, y dada la insuficiencia que 
manifiesta Aranguren para definir su libro, lo más ajustado será referirnos a él como si se tratara de una verdadera autobiografía intelectual, según se indicó.

Desde el primer capítulo encontramos una clara deuda con Crítica y meditación, pues allí reproduce entre comillas su texto «Nuestra Señora del Recuerdo», referido al colegio que los jesuitas tenían en Chamartín de la Rosa, donde compartió años de internado con José Antonio Muñoz Rojas, según hemos $v^{\text {visto }}{ }^{2}$. No se puede empezar con pie más firme. En lugar de reescribir el episodio, suscribe lo que había dicho quince años antes sobre él. Este texto, por otro lado, actúa como detonante, como catalizador para que se active el recuerdo, y así nos convoca Aranguren al siguiente capítulo, donde narra sus años de formación hasta la Guerra Civil. De hecho, según Aranguren, «hasta la guerra civil no logré la concentración, la, para repetir la expresión orteguiana, asistencia a mi propia existencia» (Aranguren 1969, p. 38). Por eso, no debe extrañarnos que la incorporación de Aranguren al grupo de intelectuales aparecido durante la Guerra Civil sea un tanto tardía, pues no tiene producción intelectual anterior a la contienda. Ésta no sólo le confirió la conciencia de la propia existencia, sino que despertó en él el «fervor religioso», a lo que contribuyó no poco una serie de lecturas realizadas durante su estancia en Toledo. Aranguren se mantuvo durante un tiempo alejado de la guerra, no fue alférez provisional y, al final, sirvió como artillero.

Tras la contienda, Aranguren cayó enfermo y hubo de buscar la tranquilidad y serenidad del campo. Fue entonces cuando se replanteó su tarea intelectual, que pretendía realizar por la vía universitaria. Las primeras labores intelectuales de Aranguren se orientaron hacia dos autores bastante alejados en el tiempo. Él mismo lo señala en la conclusión del capítulo cuarto: «mi primer libro en realidad fue dedicado a San Juan de la Cruz y solamente el segundo a Eugenio d'Ors. Autores muy diferentes ¿verdad? Y también, no podía ser de otro modo, las obras a uno y otro consagradas. ¿Qué hacer, a partir de ellas, ahora que ya había dejado de ser inédito? ¿Por dónde continuar?» (Aranguren 1969, p. 60). Con esas dos obras a las que se refiere se inicia una de las trayectorias más interesantes de toda nuestra postguerra, que tuvo en José Luis López Aranguren a uno de sus más agudos ensayistas. En el capítulo quinto, Aranguren relata los inicios de la amistad con los diferentes miembros de la generación del 36, a la que pertenecía por edad, y ahora ya por derecho, tras la publicación de sus primeros trabajos intelectuales:

${ }^{2}$ Curiosamente, en este mismo colegio de Nuestra Señora del Recuerdo estuvo como alumno interno Dionisio Ridruejo en el curso 1926-27. 
Entre tanto establecí una relación de amistad estrecha con Luis Felipe Vivanco, a quien conocí en casa de d'Ors, y con Luis Rosales, por la revista Escorial. A través de ellos, conocí a Leopoldo Panero. Los cuatro éramos de la misma edad casi exactamente, Luis Felipe un poco mayor, Luis Rosales un año menor que Panero y que yo. Con ellos y conmigo intimó José María Valverde, bastante más joven que nosotros. Las reuniones en la casa de Juana Mordó facilitaron el asiduo contacto entre nosotros, también con Pedro Laín y con otros escritores y artistas. Durante algunos años constituimos un grupo literario, ya que no la «generación del 36» que, en el supuesto de que exista, comprendería a muchos escritores más, y no, en cambio, a José María Valverde. La función que dentro del grupo asumí fue algo así como la de su crítico (Aranguren 1969, pp. 63-64).

Lo más interesante de este capítulo es ver cómo Aranguren, identificado con estos autores, se vincula vital e intelectualmente a ellos. Aunque él no tuvo un papel políticamente destacado durante la guerra, como sus compañeros, emprendería con ellos el camino que habría de conducirles al desencanto. En la primera postguerra, todos estos intelectuales vieron que lo que había resultado de la contienda no era lo que querían, de ahí que se refugiaran en las realidades más cotidianas, como los amigos, la casa y la familia. Esto se puede ver perfectamente en la evolución poética de autores como Leopoldo Panero, Luis Rosales, Luis Felipe Vivanco y Dionisio Ridruejo -lo veremos también en la evolución política de Ridruejo y en la vital de Laín-, pero, según Aranguren, no sólo los poetas, sino todos los miembros del grupo fueron en busca de Dios, $y$, para eso, se refugiaron en la vida privada, de puertas adentro:

$\mathrm{Al}$ sentirnos totalmente ajenos al rostro público de la vida española de la época, es normal que nos retrajésemos a la vida privada, la del hogar, la del amor a la mujer, el cariño a los hijos, la fraternidad con los amigos, la consideración filosófico-poética del tiempo en su pasar y en su recuerdo, de la muerte en su lento acercarse; y que nos retrajésemos también a una vida religioso-trascendente, vida unamuniana, pero aserenada, a la búsqueda y encuentro de Dios (Aranguren 1969, p. 65).

Por eso, aunque Aranguren pueda presentar alguna reticencia a la hora de emplear el marbete de generación del 36 en sentido intelectual o literario, lo cierto es que está totalmente de acuerdo con Pedro Laín cuando éste afirma que los hombres del 36, entendiendo esto más bien en sentido sociológico, fueron marcados de manera indeleble por la guerra, cuyas consecuencias se prolongaron durante una larguísima postguerra. Paradójicamente, esto fue cierto también para aquellos intelectuales que habían salido vencedores en la contienda, ya que pronto comprobaron cómo cualquier intento serio de reconstrucción cultural era desplazado de la vida pública y cómo se habían convertido en un estorbo para el régi- 
men que ellos mismos habían ayudado a instaurar. Reproducimos a continuación algunas de las reflexiones de Aranguren, quien, no lo olvidemos, al referirse a «los hombres de 1936» está aludiendo a toda una generación histórica de la que el grupo de intelectuales a que pertenecían Laín y Aranguren era sólo una parte:

Los hombres de 1936 fuimos los, por usar una expresiva palabra de Pedro Laín, empleada por él en otro contexto, «arrojados» a la guerra; arrojados porque la vivieron con arrojo, arrojados porque lo fueron a la cárcel, al exilio; arrojados porque lo fueron de su modo de vida, teniéndola que volver a empezar; arrojados también, y a cientos de miles, de la vida misma; arrojados, en fin, y a esto quería llegar, dentro de sí mismos o, a lo sumo, a una vida privada interpersonal, confinados en ella porque, más o menos oscuramente, teníamos conciencia de que, en la vida pública, a la que no se puede nunca renunciar sin mutilarse, estábamos de más (Aranguren 1969, p. 67).

Posteriormente, Aranguren se alejaría de estos autores, como ya vimos a propósito de Crítica y meditación. La «misión poética» por Hispanoamérica en que Luis Rosales y Leopoldo Panero tomaron parte contribuyó no poco a ello, pues, hasta cierto punto, implicaba hacer propaganda del régimen fuera de sus fronteras. Curiosamente, tal como señala el propio Aranguren, el mismo año que Leopoldo Panero publicaba su Canto personal -1953-, él publicaba «La evolución espiritual de los intelectuales españoles en la emigración», primer artículo que, desde la península, abordaba el exilio intelectual español. Durante algunos años, Aranguren estuvo vinculado al sector católico más renovador del país: se ocupaba de la sección «También entre los libros anda el Señor» del Correo literario y preparaba, al mismo tiempo, los libros Catolicismo y protestantismo como forma de existencia, La ética de Ortega y Catolicismo día tras día. El capítulo séptimo de Memorias y esperanzas españolas lo dedica precisamente al primer libro, uno de sus textos fundamentales.

El capítulo octavo señala el paso de Joaquín Ruiz-Giménez por el Ministerio de Educación. Fueron años en que parecía que iba a cambiar lo que no se podía cambiar. Laín era rector en Madrid y Antonio Tovar en Salamanca. Fue entonces, en el período 1951-1956, cuando Aranguren accedió a la Cátedra de Ética y Sociología de la Universidad de Madrid. Aranguren fue catedrático desde 1955 hasta 1965, cuando lo destituyeron del cargo, como veremos más adelante. A partir del capítulo noveno, Aranguren relata su periplo académico, organizando cursos, seminarios y demás, y también su aventura intelectual, trabajando en libros orientados hacia esas ramas del saber. Del mismo modo, desarrolló su labor intelectual en campos afines a la ética tanto como a la política. Durante esos años se fue distanciando claramente de los sectores más reaccionarios del régimen, que eran los que realmente ocupaban el poder. Desde su posición de intelectual, había 
decidido ejercer de una manera libre su tarea como educador. Para Aranguren, el intelectual viene a ser un moralista y ha de alzarse necesariamente contra la injusticia:

Ser intelectual no es lo mismo, pues, que ser «filósofo» 0 «ensayista», escritor. Éstos pueden proporcionar satisfacción a la sociedad, o a grupos de la sociedad muy minoritarios y selectos. El intelectual, no. El intelectual es incómodo, es un aguafiestas, con su manía de estar diciendo siempre «no» a la injusticia. Al intelectual no se le admira; en el mejor de los casos se dice de él, «(Qué lástima!», y, en el peor, se produce el, entre nosotros tan frecuente, odio al intelectual.

Pero tiene razón Carlos Castilla: es verdad que la función del intelectual parece estar hoy «vacante», porque quienes podrían desempeñarla hablan para el grupo a que pertenecen, al que les gusta pertenecer, no para la sociedad de hoy y menos para la de mañana. $Y$ ni se sienten solidarios de la sociedad, ni la soledad es autocrítica de su instalación en ella, sino mera autoprotección, «distancia» y aislado perfeccionismo esteticista, espectacular. El intelectual de otra época vivía, al menos, monásticamente, encerrado en la famosa «torre de marfil». El de ahora necesita ser aplaudido... pero sin correr riesgos reales, porque sabe «hasta dónde se puede llegar demasiado lejos» según la aguda expresión de Cocteau.

Bueno, yo, en la medida de mis escasas, modestas fuerzas, he querido desempeñar la función del intelectual, es decir, de moralista de nuestro tiempo. Como decía al final del capítulo anterior, era éste, a mi parecer, el otro lado de la cátedra de Ética, el que mira no a la teoría, el que mira a la realidad moral (Aranguren 1969, pp. 115-116).

En definitiva, lo que tenemos en Memorias y esperanzas españolas es el testimonio de un intelectual que ha desempeñado su labor como tal dentro del marco histórico de la postguerra. Vinculado en principio a un grupo que consideró integrador e intelectualmente sólido, muchos de sus miembros se desengañaron ante la imposibilidad del cambio; Aranguren también, e inició una andadura en solitario, aunque manteniendo aquellas amistades. En el capítulo XV de Memorias y esperanzas españolas relata su cese como catedrático, motivado por su participación en la primera Asamblea Libre de estudiantes. Aranguren no quiso renunciar nunca a su condición de intelectual, aunque eso le obligara a trabajar fuera de España durante algunos años:

«Memorias»y «Esperanzas» he escrito en el título de este libro. Las memorias, aunque se refieren a los otros y, en especial, a mis compatriotas, son, sobre todo, mías: constituyen mi punto de vista, mi experiencia en torno a los problemas de España. Las «Esperanzas», en cambio, me trascienden y 
son mucho más que mías, en las vísperas de cumplir sesenta años de edad. Esperanzas en España de España y para España, donde, como conté en el capítulo XV, sigo viviendo físicamente más de la mitad de mi vida $\mathrm{y}$, de verdad, está puesta ella toda entera (Aranguren 1969, p. 222).

Aranguren, cuya proyección política es bastante menor que la de Pedro Laín y Dionisio Ridruejo, fue el primero que decidió relatar su experiencia intelectual. Pronto le seguiría Pedro Laín Entralgo con su Descargo de conciencia, un libro fundamental para entender el intento de reconstrucción cultural iniciado tras la guerra y para dilucidar el papel que hubo de desempeñar cierta intelectualidad durante aquellos años.

\section{DESCARGo de CONCIENCIA, DE PEDRO LAÍN ENTRALGO}

Descargo de conciencia (1930-1960), por muchas razones, puede ser considerado como el paradigma del libro de memorias en clave de palinodia o retractación pública. Apareció en 1976 y muy pronto se desató la polémica en torno a lo que había dicho y, sobre todo, a lo que no había dicho Laín. Descargo de conciencia tuvo mucha mayor resonancia que las Memorias y esperanzas españolas de Aranguren, y esto por varias razones. En primer lugar, Laín todavía era considerado por algunos como uno de los representantes oficiales de la cultura durante el franquismo, aunque hacía años que había sido apartado de cargos de relevancia. En segundo lugar, el libro apareció en una fecha clave para la Historia de España, cuando no se sabía qué consecuencias políticas iba a tener un régimen de casi cuarenta años de duración. En tercer lugar, muchos creyeron ver que lo que hacía realmente Laín Entralgo era evadir los asuntos más importantes y eludir sus implicaciones más directas con el régimen.

Pero lo cierto es que, a unos años vista, el texto de Laín no sólo se convierte en fundamental para conocer una época cada vez más distante, sino que supone un ejercicio de autorreflexión y retractación pública que sólo un hombre honesto sería capaz de hacer. El texto no es, ni mucho menos, una particular caza de brujas donde el primero en confesar acusa a todos los demás, sino la proyección crítica que un intelectual de honda formación humanística realiza sobre su vida, asumiendo y reconociendo los propios errores. De hecho, Descargo de conciencia es sobre todo un ejemplo de integridad y una justificación que se hace extensiva a todos los miembros del grupo de que venimos hablando, convirtiéndose, por tanto, casi en un manifiesto del mismo hecho a posteriori. 
Laín podía haber contado más y con más detalle, por supuesto; sin embargo, se conformó con recordar críticamente su vida y su trayectoria intelectual, una de las más fructíferas de todos estos años. Porque, si bien es cierto que durante la Guerra Civil una serie de jóvenes intelectuales, entre los cuales él se contaba, apoyaron decididamente el alzamiento militar, no menos cierto es que lo que pretendían conseguir no era lo que después se consolidó, ni mucho menos. Lucharon por algo que fracasó, y, al acabar la guerra, tuvieron que seguir luchando, aunque ya de otro modo. Descargo dé conciencia es, entre otras cosas, una crónica de aquella lucha, de aquel intento por parte de unos intelectuales por reconstruir todo el panorama cultural que se había visto interrumpido por la contienda. Algunos críticos creen que en lugar de un libro de memorias se trata de un libro de desmemorias, ya que, no en vano, fueron muchas las cosas que Laín dejó en el tintero, sobre todo las referidas a su etapa más netamente falangista y comprometida con la sublevación militar. Pero, como se dijo, Laín hace una lectura crítica de su vida partiendo de una evolución ideológica posterior, de ahí que no incida en aquellas posiciones con la que no está de acuerdo en el momento de redacción del libro.

Desde el mismo prólogo, el autor enuncia las pretensiones de su particular descargo, que abarca principalmente los años que van de 1930 a 1960, cuando su vida tuvo una mayor dimensión pública: «Este libro quiere ser dos cosas tan distintas entre sí como entre sí conexas: una exploración memorativa de mi propia realidad y un testimonio crítico de lo que durante los treinta años más centrales de mi vida han sido ante mí y dentro de mí la historia y la sociedad de España; años en los cuales, ahora lo veo, en el constante empeño de buscarme a mí mismo tuvo mi existencia una de sus claves más secretas» (Laín Entralgo 1989, p. 13). En este sentido, no se trata de un libro de carácter histórico, sino que en él todo queda filtrado por la personalidad, por la subjetividad, de Laín - «las noticias relativas a los sucesos que solemos llamar históricos no tienen aquí otra procedencia que mi recuerdo de ellos» (Laín Entralgo 1989, p. 15)-, lo que, por otra parte, es habitual en los escritos de carácter autobiográfico, donde lo histórico cede paso a la percepción subjetiva de lo histórico.

Descargo de conciencia es un texto bastante amplio dividido en nueve largos capítulos, el primero de los cuales actúa como introducción y el último como epílogo. La Guerra Civil es el tema fundamental de los tres capítulos centrales, donde Laín Entralgo relata su paso por las ciudades más importantes del bando nacional. Cada capítulo viene rematado por un apartado que el autor denomina epicrisis, término que toma de la medicina entendiéndolo como el «juicio razonado que el médico establece acerca de lo que en su realidad ha sido la dolencia 
de un enfermo» (Laín Entralgo 1989, p. 76); esto es, al final de cada capítulo, Laín realiza un ejercicio crítico proyectando su yo del momento -1975-1976- sobre el yo de entonces. Se interroga ante sí mismo, realizando las labores de acusado y acusador ${ }^{3}$. No hay por parte de Laín, ni mucho menos, un intento de autojustificación, pero sí de reflexión crítica sobre los propios errores. Sin embargo, y como ya apuntó Aranguren en su momento, tanto la obra como la persona de Laín siempre han despertado bastantes recelos: «Una de las cosas más difícilmente comprensibles para quien no cuente siempre con la fabulosa capacidad de resentimiento de bastantes compatriotas nuestros, es la animadversión que, en ciertos sectores, han despertado la obra y la figura de Pedro Laín» (Aranguren 1977, p. 167).

Y es que, no en vano, la presentación pública de Descargo de conciencia fue uno de los acontecimientos culturales más esperados de 1976, tal y como apuntó Francisco Vega Díaz en Ínsula. En tanto que rector de la Universidad de Madrid entre 1951 y 1956, Laín había jugado un papel político de gran relevancia. En Laín, y eso es algo que podemos ver en Descargo de conciencia, asistimos a un sucesivo desencanto, pues se van desmoronando todas las esperanzas e ilusiones a las que aspiraba. No obstante, a ese desencanto no desemboca él únicamente, sino todo el grupo de intelectuales que, como él, habían pensado en un renacer de la cultura española y se habían agrupado en torno a la revista Escorial, ejemplo de una actitud «asuntiva y superadora» que fracasó desde el principio. Este desencanto, común a casi todos los fundadores de la revista Escorial, lo apunta Agustín Albarracín en su libro de conversaciones con Pedro Laín Entralgo, Pedro Lain, historia de una utopía ${ }^{4}$. Se trataría de un desencanto progresivo que

${ }^{3}$ Así lo indica Juan Pedro Quiñonero: «Laín, al final de cada capítulo, ha incluido unos diálogos morales que titula genéricamente Epicrisis (derivada directamente del griego "epikrisis", "decisión" o "determinación"), que ilustran con sus dudas e incertidumbres (el estilo literario de Laín utiliza obsesivamente la interrogación sin respuesta como recurso filosofico), la peripecia y el anecdotario» (Quiñonero 1976, p. 6).

${ }^{4}$ Agustín Albarracín divide la peripecia vital de Laín Entralgo en cinco períodos, marcados todos ellos por acontecimientos históricos fundamentales: «Porque a poco que conozcamos su biografía, es tarea fácil dividirla en una serie de períodos, cinco según mi cuenta, durante los cuales fue siendo niño, joven, adulto y ahora senecto: la España caciquil, rural y conflictiva de su niñez aragonesa y navarra primero, de su juventud bachiller y universitaria, concluida en Pamplona, Zaragoza y Valencia; la España todavía más conflictiva, sobre todo socialmente, de la II República -vivida por él en Madrid y Valencia-; la España dramática, trágica, terrible de la guerra civil, iniciada en Pamplona y proseguida en Burgos; la España que me atrevo a llamar -luego veremos por qué- del desencanto, con el desmoronamiento de ilusiones, proyectos y utopías en tanto que se consolida su vida personal universitaria, intelectual y pública; la España, en fin, nacida con el retorno de la democracia, en la que, más pasiva que activamente, sigue viviendo, esperando y padeciendo Pedro Laín» (Albarracín 1994, pp. 13-14). 
Laín fue viviendo conforme se prolongaba lo que se ha venido llamando el franquismo, considerado por muchos una etapa provisional que, a la postre, se convirtió en definitiva.

En el primer capítulo de Descargo de conciencia, titulado «Introducción», encontramos los recuerdos de infancia y primera juventud, incluyendo los años de formación. La fecha que marca la separación entre una etapa y otra es 1930 , cuando Laín llega a Madrid. Esa llegada a Madrid motiva el título del segundo capítulo, «Madrid cambiante», donde Laín asiste al advenimiento de la Segunda República mientras cursa estudios de doctorado y todavía pretende continuar su carrera dentro de la psiquiatría. Pronto abandonaría esta intención, como se puede comprobar en el tercer capítulo, «No sólo psiquiatra». Allí cuenta su estancia en Viena durante 1932, su posterior regreso a España, donde tuvo varios trabajos como médico, al tiempo que se casó con su novia, Milagro, con quien tuvo una hija en 1935. La guerra lo sorprendió en Santander, donde, alejado de su familia, impartía unos cursos con Barcia Goyanes. Los capítulos dedicados a la guerra son tres: «Guerra civil: de Santander a Pamplona», «Guerra civil: Navarra y otras tierras» y «Guerra civil: de Burgos a Madrid». En Santander, tomado por el Frente Popular, estuvo retenido Laín durante un mes. Después salió de España para entrar inmediatamente, pero esta vez por el lado de los sublevados, y con Pamplona como fin de trayecto. En Pamplona, Laín se presentó en el hospital, donde le dijeron que no requerían sus servicios. Decidió, entonces, militar en Falange: «La veía como una versión española del fascismo italiano y el nacionalsocialismo alemán; y aunque la figura de José Antonio Primo de Rivera me fuese, por lo oído, más bien simpática, la organización militar de su Movimiento y su proclamación de la violencia como instrumento de acción política no me atraían de manera especial» (Laín Entralgo 1989, p. 184). Como vemos, Laín es «camisa nueva», pero esa militancia falangista iba a propiciar su adhesión al inicial grupo de Pamplona, luego trasladado a Burgos bajo las órdenes de Dionisio Ridruejo.

En Pamplona Pedro Laín colaboró en el periódico Arriba España desde el invierno de 1936 hasta 1937. Arriba España era el «primer diario de Falange» y estaba dirigido por el sacerdote Fermín Yzurdiaga y el impresor Ángel María Pascual, quienes luego habrían de auspiciar la aventura de Jerarquía, precedente inmediato de Escorial. Durante su permanencia en Pamplona, dos actividades se reparten el tiempo de Laín, viajes y encuentros:

Viajes a San Sebastián, casi siempre con don Fermín Yzurdiaga -iqué hermosura la de los bosques y helechales del Puerto de Velate, cuando en la noche otoñal se hacían cobrizos o llameantes a la luz de los faros del automó- 
vil!-, a Segovia, a Zaragoza, a Salamanca, a Palencia. Encuentros, iniciadores algunos de amistades para siempre, con Dionisio Ridruejo, Gonzalo Torrente Ballester, Agustín de Foxá, Luis Rosales, Antonio Tovar, Carlos Jiménez Díaz, Ramón Serrano Suñer, Luis Felipe Vivanco, María Josefa Viñamata, Ernesto Giménez Caballero, Eugenio d'Ors y otros que en el curso del relato irán apareciendo (Laín Entralgo 1989, p. 204).

Efectivamente, es ya en esta etapa de Pamplona cuando empieza a prefigurarse el grupo intelectual más importante de la inmediata postguerra, el que se articularía en torno a las páginas de Escorial. Precisamente allí fue a refugiarse Luis Rosales, que venía huyendo de Granada, donde se había cometido el asesinato de García Lorca a pesar de la ayuda que le brindó al poeta la familia Rosales. Sin embargo, la empresa cultural más importante en la que participó Pedro Laín durante su estancia en Pamplona no fueron sus colaboraciones en Arriba España, sino su aportación a las páginas de Jerarquía, una auténtica rareza tipográfica:

No bastaba a la ambición fundacional de don Fermín Yzurdiaga la creación de Arriba España. Ad maiora nitens, como el Agrícola tacitiano, quiso dar al mundo una revista que respecto de todas las anteriormente publicadas en España, Revista de Occidente, Cruz y Raya, Acción Española, o Tierra firme, fuese, como suele decirse, el no va más. Su título, Jerarquía; su subtítulo, «Revista Negra de la Falange», para que la raigambre italo-fascista de su estética quedase más y más patente; su cubierta, por tanto, negra. Consiguió la ayuda económica necesaria, puso en jaque todas las posibilidades de la imprenta de Aramburu, y tras muchas pruebas y contrapruebas, siempre a su lado la experta ayuda de Ángel María Pascual, logró dar término a la impresión del primer número. Un redicho y engolado ensayete mío iba en sus páginas. Impresionaba, desde luego, el gran formato y el oro del título sobre el negro mate de la cubierta, y en el interior la calidad de los tipos, la riqueza de las tintas, el negro, el rojo y el azul de las clásicas artes de imprimir, la profusión de culs-de-lampe y adornos adicionales. Un alarde tipográfico, y más aún pensando que su cuna era una ciudad de segundo orden, y una terrible guerra civil su ocasión; aun cuando el conjunto, eso sí, resultase desmesuradamente suntuoso. Si Valle-Inclán llamó «bárbaro, funerario y catalán»-tras este último adjetivo, Gaudí- al lujo de los herrajes de un balcón gallego, «barroca, funeraria y tropical» habría que llamar, por lo menos, a la negra y rojiazul suntuosidad de aquel número de Jerarquía (Laín Entralgo 1989, pp. 214-215).

La estancia de Pedro Laín en Pamplona concluyó cuando Dionisio Ridruejo fue nombrado Jefe del Servicio Nacional de Propaganda. Pedro Laín, bajo sus órdenes, se ocuparía de la Sección de Ediciones, pero eso sería ya en Burgos. En la Sección de Ediciones, el origen de lo que luego sería la Editora Nacional, Laín contaba con un equipo de lujo: Antonio Macipe, Luis Rosales, Luis Felipe 
Vivanco, Gonzalo Torrente Ballester y, posteriormente, Carlos Alonso del Real y Melchor Fernández Almagro. En esos tiempos, aquella empresa «asuntiva y superadora» todavía estaba cargada de ilusiones, pero pronto se habrían de truncar todas sus esperanzas, al chocar con la intolerancia de las altas esferas políticas. Así define a aquel grupo el propio Laín: «una suerte de segregada "reserva literaria", un ghetto al revés, un aderezo para el lucimiento, sólo políticamente aceptable mientras no tratase de intervenir en las decisiones "serias". Los verdaderos titulares del mando nunca pasaron y nunca pasarian de tolerarnos» (Laín Entralgo 1989 , p. 235). Fue precisamente durante los años de la Guerra Civil cuando Laín se orientó hacia el campo que más habría de cultivar profesionalmente, la Historia de la Medicina. Al acabar la contienda, gran parte de los intelectuales que habían estado en Burgos bajo las órdenes de Ridruejo marcharon a Madrid, encargados de reconstruir todo un panorama cultural e ilusionados por poder hacerlo desde una actitud integradora. Pronto chocarían con la intransigencia del régimen, pero su empeño nos ha legado uno de los testimonios más fehacientes de aquella actitud: la revista Escorial.

Y así llegamos al capítulo «Otro Madrid, otros caminos», el más largo de Descargo de conciencia, donde Laín intenta dar cuenta del papel que él y su grupo jugaron durante los primeros años del franquismo. Laín continuó al frente de la Sección de Ediciones, reconvertida ya en Editora Nacional. Sin embargo, pronto habría de abandonar su labor editorial en favor de su actividad académica: catedrático de Historia de la Medicina en la Universidad de Madrid desde 1942. La aventura cultural más interesante de aquellos primeros años de postguerra iba a ser precisamente la publicación de la revista Escorial, cuyo primer número vio la luz en noviembre de 1940. Aunque pronto hubo de abandonar su talante integrador, supuso un verdadero hito dentro de la cultura de los años cuarenta, influyendo en publicaciones posteriores.

${ }^{5}$ A aquella aventura cultural le dedica Pedro Laín algunos párrafos de su Descargo de conciencia; los reproducimos a continuación: «Dentro de este contexto hay que situar, si quiere entendérsela en su integridad, la aventura que fueron los primeros años de la revista Escorial. "Interesaba de mucho tiempo atrás a la Falange la creación de una revista que fuese residencia y mirador de la intelectualidad española", dice anónimamente a través de la pluma de Dionisio Ridruejo, la letra de su "Manifiesto editorial". En efecto. Respecto de Jerarquia, dicho queda lo suficiente. Apenas conclusa la guerra, en mayo de 1939, proponía yo oficial y pormenorizadamente a Ramón Serrano Suñer la publicación de una ambiciosa Revista de las Españas, que nunca vio la luz. Pero, por diversas razones, la realización de ese atmosférico proyecto fue posponiéndose hasta noviembre de 1940, mes en el cual apareció el primer número de Escorial. Dionisio, inventor del título, fue su director; yo, su subdirector; y con nosotros compartieron la gerencia diaria del empeño, todos en amistoso régimen de igualdad, Luis Rosales y Antonio Marichalar, a quien Dionisio tuvo el acierto de llamar, para que quedase bien patente nuestra actitud frente a la cultura española anterior al 18 de julio de 1936. / El propósito inmediato de Escorial -"integración de valores"; sincero llamamiento a "todos los intelectua- 
Escorial fue, en parte, una aventura truncada. La imposibilidad de reconstruir el panorama cultural español manteniendo unos mínimos de integridad y tolerancia hizo evolucionar ideológicamente a la intelectualidad que, en un primer momento, había apoyado al régimen. El primer gran disidente explícito, como se dijo y se verá después, fue Dionisio Ridruejo; pero todos los protagonistas de aquel episodio podrían suscribir estas palabras de Laín: «la definitiva realidad es que el fracaso político-intelectual de quienes habíamos fundado Escorial, los ingenuos falangistas del ghetto al revés, se hizo cada vez más profundo y patente» (Laín Entralgo 1989, p. 291).

Con todo, donde de manera más sincera muestra Pedro Laín su arrepentimiento es cuando confiesa la simpatía que había manifestado hacia la Alemania nazi, basada fundamentalmente en afinidades formativas -su formación intelectual era principalmente germánica-. Laín asegura que, a pesar de sus viajes a Alemania, desconocía la existencia de campos de concentración: «Bajo palabra

les y escritores en función de tales y para que ejerzan lo mejor que puedan su oficio"- tuvo adecuada expresión legible en la lísta de colaboradores durante el primer año de su vida. Estábamos en ella, desde luego, muchos de los que nos habíamos congregado en Burgos: Dionisio, Tovar, Rosales, Vivanco, Torrente, Conde, Salas, Alonso del Real, yo mismo. Estaban también, cómo no, varios de los escritores falangistas anteriores a la guerra civil: Montes, Alfaro, Santa Marina, Emiliano Aguado, Samuel Ros. Junto a unos y otros, jóvenes que muy poco antes habían iniciado su carrera literaria o que de este modo la iniciaban: Caro Baroja, Cunqueiro, Díez del Corral, Fernando Gutiérrez, Gómez Arboleya, Maravall, Marías, Muñoz Rojas, Orozco, Panero, Riquer, del Rosal, Sopeña, Suárez Carreño. Y presidiéndonos a todos, esto es lo decisivo, no pocos de los hombres que con anterioridad a 1936, fuese cual fuere su ideología, habían brillado con luz propia en el cielo de nuestra cultura; entre otros, mencionados por orden alfabético, Dámaso Alonso, Azorín, Baroja, Cossío, Gerardo Diego, Fernández Almagro, García Gómez, Lafuente Ferrari, Marañón, Menéndez Pidal, Ors, Zaraguieta, Zubiri. Ausente de esa lista, ¿necesitaré decir que Ortega estaba muy presente entre nosotros? / Debo repetir aquí una advertencia ya varias veces apuntada. En modo alguno suscribiría ahora todo lo que entonces se dijo en Escorial, comenzando por lo que escribí yo mismo; pero sinceramente creo que a la revista nunca le faltó decoro intelectual y literario, hablen por sí todos esos nombres, y que dentro de aquella difícil situación de la inteligencia y las letras algo representó su aparición en la historia de nuestra cultura contemporánea. Otro tanto cabe decir de las conferencias, las lecturas, los conciertos, las exposiciones y las tertulias a que dio marco el salón de la revista. Sin llegar, desde luego, al nivel deseable, lo que hicimos tuvo llaneza, calidad y -en el seno de una España tan enfatizada- sentido del humor. Más aún: demostró con hechos y palabras nuestra voluntad de poner sobre el pavés todo cuanto en España realmente valiera y nuestro deseo de ampliar hasta donde fuese posible, penetrando, incluso, en el mundo del exilio, el ámbito de nuestra colaboración. Quisimos, en suma, que los mejores en el campo de la inteligencia, el arte y la técnica estuviesen donde los mejores deben estar. "Con la mente a medio formar -escribiría yo en 1948-, la vida de España nos puso en el trance de enseñar a otros más jóvenes. ¿Cómo hacerlo? ¿Fingiéndonos Adanes, declarándonos, qué fácil era, suficientes? Ni como españoles, ni como hombres nos parecía lícito". Yo y otros como yo entendimos que "nuestro deber y nuestro honor" consistían, por lo pronto, en "reclamar con la palabra y la conducta el magisterio de los seniores de nuestra generación; y con el de ellos, el de nuestros padres y el de todos nuestros abuelos supervivientes..."» (Laín Entralgo 1989, pp. 285-287). 
de honor afirmo que hasta después de la derrota de Alemania yo no había oído los nombres de Auschwitz, Dachau, Buchenwald o Mauthausen. ¿Cómo pensar, cuando pasaba por la Dachauertrasse, en Munich, que unos kilómetros más allá acontecían los horrores que en Dachau acontecieron?» (Laín Entralgo 1989, p. 316). Lo que más le sorprende es que, aunque hubo en Alemania quien le habló en contra de Hitler, nadie le habló de la existencia de los campos de concentración. En este punto, coincide con algunos testimonios de la época, pero choca violentamente con una realidad terrible. De hecho, resulta muy difícil entender hoy cómo aquel horror pudo pasar inadvertido para el resto del mundo.

A continuación, Laín da cuenta de su producción intelectual de aquellos años, muy importante, por cierto. No obstante, volvió a ser una figura de relevancia política cuando aceptó el cargo de rector de la Universidad de Madrid a petición de Joaquín Ruiz-Giménez, a la sazón Ministro de Educación Nacional. Esta peripecia la relata Laín en el capítulo «Rector, ma non troppo». Las labores ministeriales de Ruiz-Giménez pronto empezaron a verse con recelo desde las esferas políticas, y así también se juzgaron los rectorados de Laín y Tovar, en Madrid y Salamanca, respectivamente. Por tanto, en 1956, cuando diversos intentos por parte de los estudiantes de agruparse fuera de las filas del SEU desembocaron en la invasión del campus universitario por los falangistas, Laín dejó el Rectorado. Al abandonar el cargo, se desvinculó ya de esa España oficial que tanto le había desilusionado. Continuó con sus labores de catedrático y de académico (de la Historia, de la Medicina y de la Lengua). Por último, en el «Epílogo», Laín da cuenta de su experiencia vital durante los años que mediaron entre 1960 y el momento en que escribió Descargo de conciencia, alrededor de 1975.

\section{LAS CASI UNAS MEMORIAS DE DIONISIO RIDRUEJO}

Si bien es cierto que la vinculación política de Aranguren era mínima y la de Pedro Laín Entralgo fue algo mayor, la de Dionisio Ridruejo fue muy relevante. Desde muy joven, Dionisio Ridruejo ha repartido su vida Entre literatura y política, como él mismo, y de manera muy acertada, tituló uno de sus libros. Además, era «camisa vieja» y fue ocupando cargos de diversa importancia dentro de la Falange hasta ser nombrado Jefe del Servicio Nacional de Propaganda. Sin embargo, lo más llamativo de esa faceta política es su temprana disidencia, que se hizo manifiesta en 1942, al regresar de la campaña de Rusia, adonde había marchado como voluntario de la División Azul. 
Nos ocuparemos aquí de Casi unas memorias, volumen de carácter póstumo donde se reunieron textos de procedencia diversa para confeccionar las memorias de Dionisio Ridruejo. No hay, por tanto, una intención de coherencia y de unidad, sino la labor de un editor, César Armando Gómez, que ha agrupado los textos. Sí es cierto que se le propuso a Ridruejo escribir sus memorias y que él fue escribiendo algunos artículos con la pretensión de ensartarlos en algún momento, proyecto que no pudo llevar a término. César Armando Gómez también reunió, esta vez bajo el título de Sombras y bultos, muchos de los textos que Ridruejo publicó semanalmente en la revista barcelonesa Destino. En el prólogo de este segundo volumen, el editor viene a explicar la génesis de la obra que ahora nos ocupa:

Al hilo de esta idea, Dionisio bautizó su sección de remembranzas «Sombras y bultos», título donde lo literario se da la mano con lo plástico, en una cercanía muy del gusto de la sensibilidad de su autor. Se nos prometían así evocaciones y semblanzas, pinturas y relieves de toda especie, para que el sesgo inevitablemente político de los recuerdos que la gran mayoría de los lectores esperaban fuese entreverado con otros ocios y esparcimientos, los del escritor puro que fue siempre Dionisio, autor de un solo libro político y hombre cuyos avatares en los años de más dura brega con la dictadura pueden contarse por otros tantos tomos de versos. Así fueron las cosas, y por su página de Destino desfilaron, junto a los recuerdos dispersos y desgraciadamente inconclusos que me sirvieron para armar Casi unas memorias, comentarios circunstanciales, a menudo a sucesos de su querida Italia, aunque no faltasen Buster Keaton o Maurice Chevalier, y, sobre todo, la serie de calas en la obra y la persona de escritores vivos o muertos que ahora os ofrezco en forma de libro. $\mathrm{He}$ añadido un ensayo sobre Cela, prólogo a su Retablo ibérico, publicado en una colección de libros de bolsillo de escasa difusión (Gómez 1983, pp. 3-4).

Casi unas memorias está dividido en dos grandes segmentos temporales: 1912-1951 y 1952-1975. La primera parte consta de un total de diez capítulos frente a los once de la segunda. Ésta tiene un carácter misceláneo mayor que la primera-que responde a un discurso lógico en clave de memorias-, ya que en ella se incluyen cartas, artículos y otros materiales. Así, en sentido estricto, la primera parte es propiamente la escritura autobiográfica, mientras que la segunda corresponde a una selección del editor. Como ya se indicó, Dionisio Ridruejo formaba parte de Falange antes de que estallara la guerra y conocía personalmente a José Antonio Primo de Rivera, aunque su relación con él no era demasiado estrecha. Curiosamente, no sería hasta su estancia en Burgos cuando intimaría con Luis Rosales, Luis Felipe Vivanco y Pedro Laín, con quienes, sumando a Leopoldo Panero, iba a formar uno de los grupos intelectuales más coherentes de toda la postguerra -antes, el uno había oído hablar de los otros y viceversa a tra- 
vés de un amigo común, el poeta Germán Bleiberg-. Durante la guerra, Ridruejo se convirtió en uno de los oradores más brillantes de Falange y fue nombrado jefe provincial de Valladolid, contando ya desde ese momento con el apoyo de Antonio Tovar, el filólogo del grupo. Tras el Decreto de Unificación, Dionisio Ridruejo se traslada a Salamanca. Mientras tanto, en Pamplona se le había encargado la Prensa y la Propaganda al sacerdote Fermín Yzurdiaga, quien, junto con Ángel María Pascual, había fundado el diario Arriba España y la revista Jerarquía, publicaciones a las cuales nos hemos referido en el apartado dedicado a Laín:

Los largos discursos «para Dios y el César» de Yzurdiaga -llenos de flámulas y luceros- se publicaban con tipografía esmeradísima y grandes márgenes en un papel estupendo. Su acción fue poco organizativa y casi enteramente personal, pero puso en marcha una colección de libros y echó a navegar -aunque por poco tiempo- una revista lujosa, con tapas negras y rotulación en oro, que se llamó, como la italiana, Jerarquía. La calidad de la revista era indudable, pero sus páginas a varios colores, con leyendas lapidarias, su papel suntuoso y sus lindezas de adorno la hacían poco adecuada para un clima de guerra. Era muy imperial pero poco combatiente, como lo era -no escondo la mano- mucho de lo que otros escribimos y declamamos en aquella situación (Ridruejo 1976, p. 118).

Los servicios centrales del gobierno de Franco pronto fueron trasladados de Salamanca a Burgos. Ramón Serrano Suñer, entonces ministro del Interior, le ofreció la Dirección General Propaganda a Dionisio Ridruejo, quien aceptó el cargo y agrupó en Burgos al más nutrido grupo de intelectuales del bando nacional: «Después de algunas vacilaciones por mi parte, fui nombrado director general de Propaganda. El decreto debió de aparecer hacia los primeros días de febrero de 1938. Con un par de breves ausencias, duraría yo en ese servicio hasta el mes de noviembre de 1940, en que lo abandoné de modo voluntario» (Ridruejo 1976, p. 129). A pesar de que no había tratado hasta ese momento a quienes después habrían de ser amigos íntimos, Ridruejo decidió encargarles la Sección de Ediciones de su Dirección General de Propaganda, poniendo la semilla de lo que habría de ser la futura Editora Nacional, como ya se dijo:

A Pedro Laín, que tomó la dirección del Departamento de Ediciones, lo había encontrado en Pamplona durante un rápido viaje y, aunque seguía con mucho interés sus trabajos, sólo había cambiado con él un par de cartas. Lo mismo me sucedía con Rosales y Vivanco, muy gemelos entonces, con los que sólo había tenido una vaga comunicación impersonal -a través de Bleiberg-en 1935. Cierto que había sido yo mismo quien señalé el nombre de Rosales a Yzurdiaga para que compusiera la «escuadra» de su revista, indicándole que, 
a mi juicio, se trataba de la revelación poética más importante de aquellos años. A Torrente Ballester - que también trabajó en las ediciones-- me lo presentaría Laín, ya en Burgos (Ridruejo 1976, p. 136).

Como se ha apuntado anteriormente, en Burgos -y antes, en Pamplona, sin Ridruejo- ya encontramos casi plenamente formado el grupo intelectual que después fundaría Escorial. El grupo estaba a las órdenes de Dionisio Ridruejo, pero los dos grandes maestros eran Pedro Laín Entralgo y Luis Rosales. Leopoldo Panero se incorporaría después y Luis Felipe Vivanco ya era lo que después siempre fue, el más discreto y oscuro de sus miembros, aunque un gran poeta. Como Jefe de Propaganda, Ridruejo marchó a Barcelona al acabar la guerra, donde organizó de nuevo este servicio. Su intento de aperturismo -dirigirse a los catalanes en catalán- pronto fue frenado, e implicó la primera desilusión en una larga carrera de ellas. Ridruejo siguió ejerciendo como Jefe de Propaganda hasta noviembre de 1940, momento en que abandona su cargo para encargarse de la dirección de la revista Escorial ${ }^{\circ}$.

Los años 1940 y 1941 fueron para Ridruejo años de contradicción, durante los cuales se fraguó la posterior ruptura con el régimen. Si bien es cierto que, por un lado, había agrupado a los intelectuales más importantes que se habían quedado en España tras la contienda bajo la bandera de Escorial, no menos cierto es

${ }^{6} \mathrm{Al}$ igual que Laín, Ridruejo ha relatado su paso por la revista Escorial: «Hacia final de 1940 abandoné la Dirección de Propaganda y fundé -asociado con Pedro Laín Entralgo- la revista Escorial. Como secretarios de la revista figuraban el poeta Luis Rosales, que en la preguerra pertenecía al equipo de Cruz y Raya, y Antonio Marichalar, liberal de tradición que procedía del grupo de la Revista de Occidente. En la revista colaboraron prontamente hombres como Menéndez Pidal, Marañón, Zubiri, Baroja, Eugenio d'Ors, Marías y casi todos los poetas y escritores no exiliados, cualquiera que fuera su tendencia. Con la revista pretendíamos contrarrestar el clima de intolerancia intelectual desencadenado tras la guerra y crear unos supuestos de comprensión del adversario, integración de los españoles, etc. En algún número de la revista se condenó secamente -y no sin consecuencias molestas- el nombre de "Cruzada" aplicado a una guerra civil; se condenó el "exceso de arrepentimiento" de los que pasaban de izquierdistas a reaccionarios, dejándonos sin esperanza de equilibrio; se condenó, en finn, de uno u otro modo, la idea del monopolio de los vencedores y de la dogmatización de sus ideas. / Curiosa experiencia. Vista desde cerca y en plena actualidad, Escorial pareció a muchos españoles que venían de "la otra orilla", o simplemente del campo liberal, una mano tendida, un alivio, una manifestación sincera de antifanatismo y una tentativa seria de distensión. Así, pues, la lectura del primer editorial de la revista y de mi prólogo a las obras de Machado, escrito bajo la vigilancia del propio hermano del poeta, me proporcionó en aquellos días la amistad de no pocas personas de las que en la España vencedora se encontraban perdidas. La misma lectura, en cambio, me valió la repulsa más viva de hombres que estaban lejos de España o de los que leyeron todo aquello muchos años después. Y la mía misma cuando volviera a leerlo pasados quince o veinte años. Y es que, visto desde fuera y desde lejos, todo aquello tenía que parecer una farsa, un falso testimonio, un ardid de gentes aprovechadas que querían sumar y, con la suma, legitimar la causa a la que servían y cuyo reverso era el terror» (Ridruejo 1976, p. 224). 
que chocó con lo más reaccionario del régimen al intentar abrir un camino hacia la tolerancia intelectual. Quizá para huir de aquello se presentó como voluntario para la División Azul. A su vuelta, Dionisio Ridruejo ya estaba decidido a romper abiertamente con el régimen a pesar de las consecuencias que eso pudiera implicar. Dimitió de todos sus cargos políticos y renunció a la dirección de la revista Escorial, y no porque entonces hubiera evolucionado hacia una actitud democrática, sino porque vio que el general Franco había traicionado abiertamente el espíritu de la Falange joseantoniana. La respuesta del régimen no tardaría en llegar y Ridruejo fue confinado en la ciudad de Ronda, al tiempo que su nombre era silenciado en la prensa y en la literatura. Era el primer gran disidente de la España de Franco; había sido miembro del Consejo Nacional y Jefe del Servicio de Propaganda. Ahora bien, aunque Ridruejo rompió con el régimen porque éste se apartaba del falangismo, iría evolucionando con los años hacia posturas claramente democráticas.

Tras un tiempo en Ronda, Ridruejo solicitó continuar su confinamiento en Cataluña, lo que le fue concedido. En junio de 1944 se casó con Gloria Ros. Durante esos años, y hasta que se marchara a Italia, Ridruejo se relacionó con la intelectualidad catalana en pleno, colaborando en diversas publicaciones periódicas. A finales de 1948 se marchó a Roma como corresponsal de prensa, donde pasó algunos de los años más felices de su vida.

Al igual que Aranguren -aunque éste posteriormente- y Pedro Laín Entralgo, Ridruejo jugó un papel fundamental en los sucesos universitarios de 1956. Así, mientras Laín estaba al frente del Rectorado de la Universidad de Madrid, Ridruejo se encontraba en estrecha relación con diversos grupos de jóvenes, lo que, a la postre, dio con sus huesos en la cárcel en diferentes ocasiones. Quien había sido Jefe del Servicio de Propaganda se había convertido en un «paria oficial», empleando la expresión de Laín, y en un verdadero opositor al régimen desde posturas claramente democráticas. Durante los últimos años del franquismo, Ridruejo fue un residente habitual de las cárceles del franquismo. A su lado, sin embargo, no estaban los compañeros de la generación de la guerra, sino los jóvenes universitarios que después habrían de regir los destinos intelectuales y políticos de España: Miguel Sánchez Mazas Ferlosio, Ramón Tamames, José María Ruiz Gallardón, Enrique Múgica Hertzog, Javier Pradera Cortázar, Gabriel Elorriaga... Pero esa ya es otra historia, que se habrá de escribir sobre todo desde la política.

Aunque Casi unas memorias es el libro de memorias más abarcador y completo, Dionisio Ridruejo también cultivó la escritura autobiográfica en volúmenes de carácter misceláneo como Entre literatura y política y En algunas ocasiones. 
Crónicas y comentarios 1943-1956. Sin embargo, el título que aquí más nos interesa es Diario de una tregua, un diario de carácter íntimo que Ridruejo escribió a mediados de los cuarenta, durante su estancia en Cataluña, y que publicó en la prensa catalana. Como libro, Diario de una tregua se publicó por primera vez en una edición limitada en 1959, con ilustraciones de Benjamín Palencia y bajo el título Dentro del tiempo. Memorias de una tregua. Años más tarde, en 1972, apareció Diario de una tregua en la editorial Destino. De la nota previa de esta última edición provienen las siguientes afirmaciones de Ridruejo:

Las anotaciones que se encadenan en este diario fueron escritas entre los años 1945 y 1947, en San Andrés de Llavaneras, San Cugat del Vallés y Alella. Muchas aparecieron desgranadas en un periódico de Barcelona, firmadas con iniciales. En 1959 mi amigo Fernando Baeza las publicó en libro de edición numerada y limitadísima. Él cuidó la impresión y nadie lo hubiera hecho con más gusto y saber. Unos dibujos que Benjamín Palencia cedió generosamente lo enriquecieron. El título original, Memorias de una tregua, fue dejado como subtítulo, anteponiéndole, por consideraciones de estética tipográfica, el de Dentro del tiempo, a mi juicio menos adecuado. Hoy restablezco el primero corrigiéndolo por razones de oído y precisión.

Al publicar esta edición más asequible, me pregunto si no resultará en exceso «contra corriente» un libro tan pasivo y especular, donde la acción humana es tan escasa y la historia pasa de largo. Si el lector quiere hacerme un favor apoyará el acento en la palabra «tregua». El libro es el más sosegado y vegetativo de los varios que comprenderán las Memorias de un hombre que no se ha distinguido por su marginación ante los problemas del mundo (Ridruejo 1988, p. 9).

Diario de una tregua es precisamente un texto de carácter íntimo escrito por Ridruejo en Llavaneras durante los primeros años de matrimonio con Gloria Ros. Las entradas se hacen por días, aunque no todos los días tienen entrada. Son reflexiones sobre Cataluña, sobre el paisaje y sobre sí mismo. Manuel A. Penella apunta que no «hay puntos de referencia para ubicarlo al tacto o al cálculo en el contexto de la literatura contemporánea. Producto íntimo, escrito como sin sospechar futuros lectores, clandestino, el libro ha tenido, sin duda, que superar repetidos obstáculos antes de que Ridruejo se decidiese a lanzarlo a la calle» (Penella 1973, pp. 180-181).

Aunque en este apartado nos hayamos centrado fundamentalmente en Casi unas memorias, no queríamos dejar de lado Diario de una tregua, pues se trata de un texto de carácter personal que puede engarzar perfectamente con el Diario de Luis Felipe Vivanco, uno de los testimonios más ilustrativos de ese sentimiento de desencanto que persiguió a todos los miembros del grupo. 


\section{LUIS FELIPE VIVANCO Y SU DIARIO}

A pesar de que el poeta Luis Felipe Vivanco ensayara la escritura autobiográfica en algunos de sus poemas y en títulos como Los ojos de Toledo, Lecciones para el hijo y Me llamo Luis Felipe Vivanco, donde ésta alcanza su máxima expresión es en su Diario, publicado en 1983 con carácter póstumo a cargo de su hija, Soledad Vivanco. En este caso ya no estamos ante unas memorias, sino ante un diario íntimo ${ }^{7}$ que otra persona se ha encargado de seleccionar y editar. Al contrario que Aranguren, Laín y Ridruejo, Luis Felipe Vivanco tuvo una menor proyección pública y, de hecho, era el más oscuro de los componentes del grupo de Escorial. De profesión arquitecto, Vivanco se mantuvo alejado de honores literarios y cargos académicos, viviendo de sus libros y, sobre todo, de su trabajo como arquitecto. Todo esto tiene una importancia fundamental dentro del diario, pues, si bien su poesía llegó hasta altas cotas de calidad literaria, él se sabía un fracasado en el sentido profesional y su familia siempre anduvo escasa de dinero.

Lo interesante de este Diario es que nos acerca a un poeta que, formando parte del grupo descrito desde el primer momento, tuvo una vida personal alejado del resto de componentes, de ahí que Francisco Umbral, en su Trilogía de Madrid, lo compare con el cuarto de los hermanos Marx. Por otra parte, Luis Felipe Vivanco no se ocupa en su diario de los años de la guerra, sino que pasa directamente a 1946, cuando su actividad intelectual es mayor. Soledad Vivanco Gefaell, su hija, nos informa de los pormenores de la edición del Diario en una nota previa que reproducimos parcialmente:

Este libro es un resumen del Diario que llevó mi padre, Luis Felipe Vivanco, de 1946 a 1971.

Cuando lo empezó tenía treinta y ocho años, hacía uno que se había casado, y siguió escribiéndolo hasta su muerte, aunque en los últimos años no trabajó mucho en él. Es un diario muy extenso; iba escribiéndolo en cuadernillos pequeños que llevaba siempre encima y que, pasados a limpio, ocupan unos cinco mil folios.

En esta primera aproximación he querido que el libro dé una idea general y lo más completa posible de cómo era él, pero sobre todo me ha parecido importante todo lo que se refiere a la creación y a su vida literaria. También he

${ }^{7}$ Para establecer la diferencia entre autobiografía y diario íntimo, podemos acudir a las definiciones de Georges Gusdorf: «El autor de un diario íntimo, anotando día a día sus impresiones y sus estados de ánimo, fija el cuadro de su realidad cotidiana sin preocupación alguna por la continuidad. La autobiografía, al contrario, exige que el hombre se sitúe a cierta distancia de sí mismo, a fin de reconstruirse en su unidad y en su identidad a través del tiempo» (Gusdorf 1991, p. 12). 
pretendido poner de relieve su actitud ante la España de su tiempo, y su forma de vivir el catolicismo. Dejo un poco de lado los «lugares vividos», los paisajes y la vida cotidiana, que son una parte muy importante del Diario. Y los últimos años, que fueron especialmente difíciles, y durante los cuales escribió las Prosas propicias, tampoco están bien reflejados aquí, porque escribió poco y además se autocensura, por problemas políticos.

Quiero recordar muy especialmente a mi madre, María Luisa Gefaell, gran escritora y gran renunciadora. Dedicó los dos años que mediaron entre su muerte y la de mi padre a poner en limpio todo el Diario. Y, por tanto, este libro es una continuación de su trabajo (Vivanco 1983, p. 9).

Como vemos, no estamos ante el diario íntegro de Luis Felipe Vivanco, sino ante una selección que ha llevado a cabo su hija, que nos entrega lo que ella considera más relevante para la dimensión literaria de su padre. Si bien es cierto que ha habido en nuestro país, durante este siglo, cierta profusión de libros de memorias y autobiografías, la verdad es que escasean bastante los diarios de carácter intimo, como es éste que ahora presentamos. Por eso, cuando este diario vio la luz fue bien recibido por la crítica. Jaime Siles, por ejemplo, tras señalar la diferencia entre diario y memorias ${ }^{8}$, sitúa el Diario de Vivanco al lado de los libros de memorias más importantes de su generación, que son precisamente los que hemos ido viendo a lo largo de este trabajo: «El Diario de Vivanco supone, además, un examen de conciencia de los paradigmas y circunstancias que conforman la Weltanschauung de su generación. En este sentido -y junto con las Memorias de Aranguren, las Casi unas memorias de Ridruejo, y el Descargo de conciencia de Laín- son un testimonio histórico de una honestidad incuestionable» (Siles 1987, p. 156). Si había algo que emparentaba a todos estos autores era precisamente la idea de desengaño, desencanto o desilusión. Por eso, en sus libros dan cuenta de un fracaso, el de la reconstrucción intelectual iniciada con la aventura aperturista de Escorial. Sin embargo, su fracaso fue sólo relativo, y esto explicaría la propia evolución desde la militancia falangista hasta actitudes democráticas. José Luis Cano, al reseñar el Diario, se centra en esa idea de desengaño, más acentuada en él que en ninguno de sus compañeros, pues Vivanco nunca encontró acomodo oficial: «Un español desengañado, como tantos, a quien amargó y destruyó la España injusta y esperpéntica que se vivió bajo los cuarenta años de

${ }^{8}$ «La literatura -sobre todo, la que se manifiesta en forma de diario- es tanto estilo como circunstancia, y, a veces, más que estilo, sólo yo, es decir, circunstancialidad. El género diario se diferencia de las Memorias precisamente en esto: en que, aun siendo, como aquéllas, expresión subjetiva del yo ante sus circunstancias, se escriben en (y desde) el durante, y no en y desde el después. EI discurso ha de ser, necesariamente, uniforme, en la medida en que el tiempo (y no la historia narrada) no lo es» (Siles 1987, p. 154). 
Franco. Su Diario es quizá uno de los testimonios más patéticos de ese dolorido desengaño» (Cano 1984, p. 9).

El Diario está dividido por años, correspondiendo la última entrada a 1975 , ya que Vivanco murió el 21 de noviembre de ese año, en fechas de gran significación política. Desde el primer momento, encontramos a lo largo de todo el texto una continua reflexión sobre la poesía en general y sobre su escritura poética en particular, que viene definida en estos términos en un apunte de 1946: «Incapacidad para interesarme de veras o emocionarme, ni poética ni humanamente, con las cosas públicas, es decir, con la política. Sentimientos íntimos como refugio contra el mundo. Este ha sido siempre el núcleo temático de mis poemas» (Vivanco 1983, p. 18). En apenas tres líneas ha venido a definir la tan traída poesía de la intrahistoria o poesía arraigada, y que, en realidad, es aquella que busca consuelo y refugio en las realidades más cotidianas e íntimas -Dios, la casa y la familia, entre otras cosas-. Esta poesía tiene a uno de sus mejores cultivadores en el propio Vivanco, pero también debemos recordar a Luis Rosales y Leopoldo Panero, amigos íntimos del poeta.

Si hay una preocupación constante a lo largo de todo el Diario es la dificultad para armonizar la vida con la obra. Como no es profesionalmente un poeta, sino un arquitecto, considera que la poesía forma parte de su vida, pero reconoce que no debe perderse la vida sólo para conseguir una mayor producción. Ésta es una de sus mayores cuitas, sobre todo en él, que había de volver eventualmente a la arquitectura para poder subsistir:

Esto es sólo vida. Pero es más importante vida que obra. Y sin embargo, tengo que dejar obra. Pero ¿cómo salir de la vida? ¿Perderme vida por culpa de la obra? Eso estaba bien de soltero.

Mi obra consiste en pertenecer, no en hacer. Por el hacer, las cosas le pertenecen a uno. Pero yo me entrego al paisaje, a María Luisa, a las niñas. Pertenezco a estas realidades. ¿Soy un místico? Por eso, no me importa mi hacer profesional, al contrario, es casi el único que hago, porque no pongo vida en él, sino defensa de la vida. Pongo mi corazón exclusivamente en mi vida, y sólo a través de ella en su defensa ¿Y mi obra poética? Forma parte de mi vida. No es mi profesión. De aquí lo importante que haya una profesión distinta, bien diferenciada. No sólo desde el punto de vista crematístico, sino también desde el vital y afectivo. Pero viviendo así, tan atenido exclusivamente a la vida, se corre el peligro de caer en lo enfermizo, que es reconocible por su infecundidad (Vivanco 1983, p. 48). 
Uno de los momentos más significativos de este Diario es cuando, tras haber asistido a una lectura de La casa encendida, de su amigo Rosales, Vivanco reflexiona sobre la obra maestra del poeta granadino y la vincula a otros libros de la misma generación, como La estancia vacía de Leopoldo Panero". Por otro lado, la vida en la ciudad siempre fue para Vivanco una manera de suplicio, ya que no podía trabajar ni escribir, al necesitar constantemente la tranquilidad y la belleza del campo, el refugio en lo humilde. Él se sabe diferente de sus amigos, «siempre seré oveja negra, al margen», ya que ellos se sienten atraídos por las luces de la ciudad y de la cultura más o menos establecida «oficialmente», según esta anotación de 1953: «(Qué felices Luis y Dionisio, que pertenecen más a la ciudad y a la cultura!» (Vivanco 1983, p. 78). Del mismo modo, Vivanco duda acerca de si es un buen poeta, pues nunca gozó de tantos honores como sus compañeros. Le atormenta pensar que su poesía puede ser mediocre, y que, en realidad, no lo tienen en cuenta precisamente por eso: «¿Por qué mi destino consiste en ser poeta mediocre y sufrir tanto? ¿Tendré que reconocerlo, por fin? ¿Habré vivido engañado hasta ahora? ¿Qué es mi obra comparada con la de los demás? Hasta ahora, seguro de mí mismo, he despreciado el que no me tuvieran más en cuenta, pero ¿tendrán razón, Dios mío? ¡Si ni siquiera te tengo a ti! ¡No tengo la forma! ¡Hay que apurar el cáliz! Y que quiera a mis hijos y los saque adelante. ¡Lo mejor para ellos!» (Vivanco 1983, p. 86).

Toda la existencia de Luis Felipe Vivanco se debate en estos mismos términos. Otro hito interesante dentro de su Diario es la muerte de Leopoldo Panero, lo que le obliga a desplazarse hasta Astorga para asistir a su entierro. Al morir Leopoldo, Vivanco le escribe una carta a Juan Panero, muerto en 1937, que es uno

'La opinión que vierte Vivanco sobre La casa encendida después de haber asistido al recital es muy valiosa: «Luis ha recitado en el Aula Poética del Ramiro de Maeztu su poema La casa encendida. La soltería solitaria en las habitaciones de su casa. Su dormitorio, sus muebles, su cama. Y, de pronto, una luz que se enciende en el cuarto trastero, a través del patio. La marcha hacia esa luz. Está allí Juan Panero. Y recuerda los días de la Facultad: sale Piedad, salen Pilar, Concha, María Josefa, María Dolores. Salgo yo. "Presupuestario y ejemplar" me llama. Y cuando se apaga esta luz y vuelve a su dormitorio, en el despacho pequeño, otra luz encendida. Lluvia, puerto de mar, embarcadero. Barca de remos que se acerca. Una figura de mujer, de colegiala. Una interrupción. Un timbre. ¿Es un timbre o una sirena? Es el médico de una sociedad. Sigue el poema: la descripción de Maruca, que se queda también en el pasado. Y otra habitación que se enciende: su biblioteca, los libros que caminan y caminan. Hablando de él. Son sus padres muertos. Su primer Corpus y las campanas de Granada sonando a Corpus... Al día siguiente, al volver a su casa, desde la calle, la ve toda encendida. Y le da gracias a Dios por ello. El poema es hermoso, vivido, vivo, dinámico, sin fallos, de un tirón. Alegre y juguetón de lenguaje, de elementos. Es un gran poema. Aún no lo he leído despacio. Tendré que hacerlo. Está en la línea de La estancia vacía, de mi Invierno, de Los ángeles diarios de Fernando Gutiérrez. Con más elementos imaginativos concretos y más acierto natural de expresión. Menos posado y grave que el de Leopoldo, menos concentrado y realista que el mío» (Vivanco 1983, p. 51). 
de los mejores homenajes que jamás se le hayan escrito a los hermanos Panero, ambos amigos de Vivanco. Al contrario que en los textos de Aranguren, Laín y Ridruejo, en el de Vivanco todo es intimidad de un alma en lucha constante consigo misma. No resulta gratuito que uno de sus mejores poemas sea precisamente la «Elegía de Cervantes», donde elogia al maestro fracasado. Él es consciente de no estar a la altura del maestro y de no merecer ese título, pero se le asemeja en ese fracaso vital que los ha unido a través de los siglos: «No hace falta haber triunfado en toda la línea (Cervantes, el gran fracasado)» (Vivanco 1983, p. 206). En ciertos aspectos, a Luis Felipe Vivanco se le puede tildar de exiliado interior, sobre todo por su situación con respecto a sus compañeros de generación. Perteneció a aquella intelectualidad de la España vencedora, pero pronto llegó el desengaño y con ella sólo compartió la amistad y las colaboraciones en revistas como Escorial. A pesar de todo, es una de las voces más genuinas de la poesía de nuestro siglo. En este sentido, resulta especialmente doloroso para Vivanco reconocer su fracaso a la altura de 1973, dos años antes de su muerte:

Si miro hacia atrás, veo que toda mi vida de casado -desde el año 45 hasta hace unos meses- ha sido una continuada y absurda angustia económi$\mathrm{ca}$, sin apenas compensaciones de orden literario. Una vida, no fracasada, sino más bien equivocada. Y la culpa ha sido de mi profesión de arquitecto. Con la literatura o poesía, nada más, hubiera vivido pobre. Pero con la arquitectura he vivido, además, maniatado. He trabajado, no sé si mucho o poco, pero sin provecho. No he tenido -en arquitectura y en literatura- más que migajas. Y esto, prescindiendo de la dimensión política del asunto, que lo empeora (Vivanco 1983, p. 233).

La sinceridad que encontramos en el texto de Vivanco no es común. Tengamos en cuenta que estamos ante un texto de carácter íntimo que probablemente no pensara publicar. Del mismo modo, su testimonio da cuenta de esa desilusión de la que hemos venido hablando, pero, en su caso, vivida de una forma más radicalizada. En cierto modo, este diario puede ser considerado como el diario de todos los miembros del grupo, aunque es cierto que los otros, al contrario que Vivanco, se refugiaron en la oposición política -en el caso de Ridruejo- y en la actividad académica -en el caso de Pedro Laín- o editorial -en el caso de Panero y Rosales-. Vivanco quedó a solas consigo mismo, lo que le permitió reflexionar sobre las lecturas, la vida pasada, el falso cristianismo y, sobre todo, la poesía, la suya, la de sus amigos y la de los maestros: Unamuno, Machado, Neruda, Vallejo, Juan Ramón... ¿Una vida fracasada? Ni como persona ni como poeta. Como intelectual, quizá, pues Vivanco renunció desde el principio a la dimensión pública del intelectual. 


\section{CODA}

A lo largo de estas páginas nos hemos acercado a los libros autobiográficos de una serie de autores que formaron lo que se ha venido llamando grupo de Escorial o grupo Rosales. Curiosamente, han quedado fuera de nuestras explicaciones dos de los autores más importantes del mencionado grupo: Luis Rosales y Leopoldo Panero. En el caso de Rosales, no contamos con ninguna publicación equiparable a las que hemos venido comentando ${ }^{10}$. En el caso de Leopoldo Panero, aunque es cierto que no contamos con ningún diario, libro de memorias o autobiografía de su autoría, no debemos olvidar la existencia de diversas publicaciones y películas que se refieren a él y a otros miembros de su familia ${ }^{11}$. De todas maneras, esta doble ausencia no ha de alterar la trayectoria común que hemos perfilado: la evolución ideológica de aquellos autores de la generación del 36 que, vencedores en la contienda, se sintieron vencidos en la postguerra. Por supuesto, esa evolución se materializará en cada caso con unas determinadas particularidades, como se ha ido viendo, pero lo cierto es que podemos mantener la afirmación de que hay un verdadero espíritu de grupo, a juzgar por lo que tienen de convergente sus respectivos libros de memorias.

1" En realidad, Luis Rosales publicó en la revista Anthropos $\left(\mathrm{n}^{\circ} 25,1983\right)$ una breve autobiografía literaria que tituló precisamente «Autobiografía literaria improvisada ante un magnetófono», recogida en el último volumen de sus Obras completas. Aunque el texto es bastante breve y se centra sobre todo en la reflexión sobre la propia actividad intelectual y literaria, allí nos explica cómo conoció a Luis Felipe Vivanco en la redacción de la revista Los cuatro vientos, y cómo Vivanco, él y Juan Panero asistían a las clases en la Facultad de Filosofía y Letras de Madrid, episodio que el propio Rosales recreó en La casa encendida. También debemos señalar la existencia de un libro de Félix Grande, La calumnia, cuyo subtítulo, De cómo a Luis Rosales, por defender a Federico García Lorca, lo persiguieron hasta la muerte, es bastante elocuente.

"Además de biografías y libros de memorias, los Panero fueron protagonistas de dos excelentes películas de carácter documental, algo completamente inaudito en el cine español. La primera de ellas fue El desencanto, de Jaime Chávarri, y la segunda Después de tantos años, de Ricardo Franco. En la primera de ellas asistimos a una verdadera autopsia espiritual del poeta Leopoldo Panero por parte de su viuda e hijos, mientras que Después de tantos años vuelve a reunir a los tres hermanos tras la muerte de la madre, Felicidad Blanc. Hasta la fecha, además, contamos con las memorias de Felicidad Blanc (Espejo de sombras) y de Juan Luis Panero (Sin rumbo cierto) y con la biografía de Leopoldo María Panero (El contorno del abismo). Tampoco debemos olvidar que esta particular familia ha servido de inspiración a diversos cuentos y novelas, como "Apagad el gas antes de iros», de Luis Antonio de Villena, Lejos de Veracruz, de Enrique Vila-Matas, y Tul ilusión, de Jorge de Cominges. 


\section{BIBLIOGRAFÍA}

ALBARRACÍN, Agustín, 1994. Pedro Laín, historia de una utopía, Madrid, Espasa-Calpe.

ARANGUREN, José Luis L[ópez], [1957] 1977. Crítica y meditación, Madrid, Taurus.

- 1969. Memorias y esperanzas españolas, Madrid, Taurus.

BENET, Juan et al., 1976. Dionisio Ridruejo, de la Falange a la oposición, Madrid, Taurus.

BENITO FERNÁNDEZ, José, 1999. El contorno del abismo. Vida y leyenda de Leopoldo María Panero, Barcelona, Tusquets.

BLANC, Felicidad, 1977. Espejo de sombras, Barcelona, Argos Vergara.

CABALLÉ, Anna, 1991. «Memorias y autobiografías en España (siglos XIX y XX)», Anthropos, Suplementos, $\mathrm{n}^{\circ} 29$, págs. 143-169.

CANO, José Luis, 1984. «Luis Felipe Vivanco: Diario, 1947-1975», Ínsula, $\mathrm{n}^{\circ}$ 447, págs. 8-9.

CARPINTERO, Helio, 1967. Cinco aventuras españolas (Ayala, Laín, Aranguren, Ferrater, Marias), Madrid, Revista de Occidente.

CORTÉS IBÁÑEZ, Emilia, 1993. «La autodiégesis en Pilar de Valderrama, Josefina Manresa y Felicidad Blanc», en José ROMERA CASTILLO (ed.), Escritura autobiográfica, Madrid, Visor, págs. 159-167.

DÍAZ-PLAJA, Guillermo, 1966. Memoria de una generación destruida (1930-1936), Barcelona, Delos-Aymá.

ESCOBAR, Luis, 2000. En cuerpo y alma. Memorias, Madrid, Temas de Hoy, $2^{a}$ edición.

GÓMEZ, César Armando, 1983. «Prólogo» a Dionisio RIDRUEJO, [1977]. Sombras y bultos, Barcelona, Destino, págs. 3-5.

GRANDE, Félix, 1987. La calumnia. De cómo a Luis Rosales, por defender a Federico García Lorca, lo persiguieron hasta la muerte, Madrid, Mondadori. 
- 1996. «La poesía de Luis Rosales: más junta que una lágrima», en Luis ROSALES, Obras completas I. Poesía, Madrid, Trotta, págs. 9-100.

GULLÓN, Ricardo, 1969. «La generación de 1936», en La invención del 98 y otros ensayos, Madrid, Gredos, págs. 162-177.

GUSDORF, Georges, [1948] 1991. «Condiciones y límites de la autobiografía», Anthropos, Suplementos, n² 29, pp. 9-18. [Traducido por Ángel G. Loureiro y publicado originalmente en Formen der Selbstdarstellung. Analekten zu einer Geschichte des literarischen Selbspotraits. Festgabe fur Fritz Neubert, Berlín, Duncker y Humblot, 1948, págs. 105-123].

LAÍN ENTRALGO, Pedro, [1976] 1989. Descargo de conciencia (1930-1960), Madrid, Alianza.

LEJEUNE, Philippe, [1975] 1991. «El pacto autobiográfico», Anthropos, Suplementos, $n^{\circ} 29$, pp. 47-61. [Traducido por Ángel G. Loureiro y publicado originalmente como primer capítulo del libro Le pacte autobiographique, París, Seuil, 1975, págs. 13-46]

LOUREIRO, Ángel G., 1991. «Bibliografía general sobre la autobiografía española», Anthropos, Suplementos, nº 29, págs. 142-143.

MAINER, José-Carlos (ed.), 1971. Falange y Literatura, Barcelona, Labor.

- 1972. «La revista Escorial en la vida literaria de su tiempo», en Literatura y pequeña burguesía en España (Notas 1890-1950), Madrid, Edicusa, págs. 241-262.

MANGINI GONZÁLEZ, Shirley, 1987. Rojos y rebeldes. La cultura de la disidencia durante el franquismo, Barcelona, Anthropos.

MERMALL, Thomas, 1978. La retórica del humanismo. La cultura española después de Ortega, Madrid, Taurus.

MORÁN, Gregorio, 1998. El maestro en el erial. Ortega y Gasset y la cultura del franquismo, Barcelona, Tusquets.

MUÑOZ ROJAS, José Antonio, 1994. La gran musaraña (Memorias), Valencia, Pre-Textos.

PANERO, Juan Luis, 2000. Sin rumbo cierto. Memorias conversadas con Fernando Valls, Barcelona, Tusquets. 
PENELLA, Manuel A., 1973. «El diario de Dionisio Ridruejo», Cuadernos Hispanoamericanos, $\mathrm{n}^{\circ} 274$, págs. 179-182.

QUIÑONERO, Juan Pedro, 1976. «Descargo de conciencia, de Laín Entralgo», Informaciones de las Artes y las Letras, $\mathrm{n}^{\circ} 411$, págs. 6-7.

RIDRUEJO, Dionisio, 1959. Dentro del tiempo. Memorias de una tregua, Barcelona, Arión.

- 1960. En algunas ocasiones. Crónicas y comentarios 1943-1956, Madrid, Aguilar.

- [1972] 1988. Diario de una tregua, Barcelona, Destino.

- 1976. Casi unas memorias, Barcelona, Planeta.

- [1977] 1983. Sombras y bultos, Barcelona, Destino.

- 1984. Diario de una tregua, Barcelona, Orbis.

ROMERA CASTILLO, José, 1991. «Panorama de la literatura autobiográfica en España (1975-1991)», Anthropos, Suplementos, nº 29, págs. 170-184.

ROSALES, Luis, 1998. «Autobiografía literaria improvisada ante un magnetófono», en Obras completas VI. La mirada creadora. Pintura, música y otros temas, Madrid, Trotta, págs. 277-289.

RUBERT de VENTÓS, Xavier, 1970. «Aranguren, entre un homenaje y unas memorias», Cuadernos para el diálogo, XXII, págs. 55-58.

SERRANO SUÑER, Ramón, 1977. Entre el silencio y la propaganda, la Historia como fue. Memorias, Barcelona, Planeta.

- 1981. De anteayer y de hoy, Barcelona, Plaza \& Janés.

SILES, Jaime, 1987. «El Diario de Luis Felipe Vivanco», Cuadernos Hispanoamericanos, $\mathrm{n}^{\circ}$ 442, págs. 154-157.

UMBRAL, Francisco, 1984. Trilogía de Madrid. Memorias, Barcelona, Planeta.

VEGA DÍAZ, Francisco, 1976. «Pedro Laín Entralgo antes y después de su Descargo de conciencia», Ínsula, $\mathrm{n}^{\circ} 358$, pág. 3 .

- 1987. «Al cumplirse diez años de Descargo de conciencia», Cuadernos Hispanoamericanos, $\mathrm{n}^{\circ}$ 446-447, págs. 128-132. 
VIVANCO, Luis Felipe, 1953. Los ojos de Toledo, Barcelona, Barna.

- 1961. Lecciones para el hijo, Madrid, Aguilar.

- 1964. Me llamo Luis Felipe Vivanco, Madrid, Aguilar.

- 1983. Diario 1946-1975, Madrid, Taurus. 